\title{
A Cross-Sectional Study of the Association between Autoantibodies and Qualitative Ultrasound Index of Bone in an Elderly Sample without Clinical Autoimmune Disease
}

\author{
Rosebella A. Iseme $\mathbb{D}^{1},{ }^{1,2}$ Mark McEvoy, ${ }^{2,3}$ Brian Kelly, ${ }^{2,4}$ Linda Agnew, ${ }^{5}$ \\ Frederick R. Walker, ${ }^{2,6,7}$ Michael Boyle, ${ }^{2,8}$ and John Attia $\mathbb{D I D}^{2,3,8}$ \\ ${ }^{1}$ Department of Population and Reproductive Health, School of Public Health, Kenyatta University, P.O. Box 43844, \\ Nairobi 00100, Kenya \\ ${ }^{2}$ School of Medicine \& Public Health, The University of Newcastle, Callaghan, NSW 2308, Australia \\ ${ }^{3}$ Hunter Medical Research Institute, Kookaburra Circuit, New Lambton Heights, NSW 2305, Australia \\ ${ }^{4}$ Centre for Brain and Mental Health Research, The University of Newcastle, Callaghan, NSW, Australia \\ ${ }^{5}$ Brain Behaviour Research Group, School of Science and Technology, University of New England, Armidale, NSW 2351, Australia \\ ${ }^{6}$ Laboratory of Affective Neuroscience, The University of Newcastle, Callaghan, NSW, Australia \\ ${ }^{7}$ University of Newcastle, Medical Sciences MS413, University Drive, Callaghan, NSW 2308, Australia \\ ${ }^{8}$ Department of General Medicine, John Hunter Hospital, New Lambton Heights, NSW, Australia
}

Correspondence should be addressed to Rosebella A. Iseme; iseme.rosebella@ku.ac.ke

Received 29 November 2017; Revised 5 March 2018; Accepted 17 March 2018; Published 30 April 2018

Academic Editor: Margarete D. Bagatini

Copyright (c) 2018 Rosebella A. Iseme et al. This is an open access article distributed under the Creative Commons Attribution License, which permits unrestricted use, distribution, and reproduction in any medium, provided the original work is properly cited.

\begin{abstract}
Bone loss is characteristic of the ageing process and a common complication of many autoimmune diseases. Research has highlighted a potential role of autoantibodies in pathologic bone loss. The confounding effects of immunomodulatory drugs make it difficult to establish the contribution of autoantibodies amongst autoimmune disease sufferers. We attempted to examine the relationship between autoantibodies and bone mass in a population of 2812 elderly participants without clinical autoimmune disease. Serum samples were assayed for a panel of autoantibodies (anti-nuclear, extractable nuclear antigen, antineutrophil cytoplasmic, thyroid peroxidase, tissue transglutaminase, anti-cardiolipin, rheumatoid factor, and cyclic citrullinated peptide). Bone mass was measured using quantitative ultrasound (QUS) of the calcaneus. The relationship between each autoantibody and bone mass was determined using linear regression models. Anti-nuclear autoantibodies were the most prevalent, positive in approximately $11 \%$, and borderline in roughly $23 \%$ of our sample. They were also the only autoantibody observed to be significantly associated with QUS index in the univariate analysis $(n=1628 ; r=-0.20 ; 95 \%$ CI: $-0.40-0.00$; $p=0.046$ ). However, statistical significance was lost after adjustment for various other potential confounders. None of the other autoantibodies was associated with QUS index in either univariate or multivariate analysis. We are limited by the cross-sectional nature of the study and the low prevalence of autoantibodies in our nonclinical sample.
\end{abstract}

\section{Introduction}

Normal bone remodelling requires a tight coupling of bone resorption to bone formation, whereby the two processes occur simultaneously and in harmony to guarantee negligible change in bone mass and therefore no alteration in bone quantity after each remodelling [1]. Loss of coupling between these two processes leads to osteoporosis, a combination of pathologic bone loss and altered microarchitecture that results in fragility fractures in response to minimal or low velocity force $[2,3]$. Osteoporosis is predominantly a condition of the elderly and accounts for approximately 2 million fractures annually, including hip, vertebral (spinal), wrist, and other fractures $[3,4]$. Osteoporotic fractures contribute 
to a marked increase in morbidity and mortality, as well as health care costs and disability amongst this cohort [3].

In recent years, pathologic bone loss has been associated with disorders characterised by immune dysfunction, hinting at the presence of an immune-skeletal interface $[5,6]$. Research aimed at elaborating this relationship has identified common cell types and shared mediators that play functional roles in both systems [7]. For example, vitamin D, parathyroid hormone (PTH), testosterone, and leptin, all recognized regulators of bone function, are also acknowledged to modulate immune function [8]. Additionally, macrophages, osteoclasts, and dendritic cells are all derived from the same myeloid precursors, with the latter two noted to exhibit the same lifecycle [9]. Notably, varieties of immune cells have been observed to regulate osteoclast and osteoblast activity in turn mediating the process of bone remodelling, responsible for maintaining the quality of the skeleton [10]. It therefore stands to reason that perturbations in the immune system would translate into disruptions in bone homeostasis.

The emergence of the field of osteoimmunology has recognized the immune system as a vital player in fine-tuning the balance between bone resorption and bone formation [11]. Though the role of inflammatory cytokines such as tumor necrosis factor alpha (TNF $\alpha)$, interleukin- (IL-) $1 \beta$, and IL- 6 in enhancing osteoclast-mediated bone resorption is well established, the involvement of autoantibodies is still poorly defined [12]. Nevertheless, the findings of our recent literature review provided strong evidence justifying further research aimed at delineating the relationship between autoantibodies and bone mineral density (BMD) [13]. Autoantibodies against a myriad of antigens have been linked to pathologic bone loss [14-20]. For instance, autoantibodies against rheumatoid factor (RHF) and anti-cyclic citrullinated peptide autoantibodies (anti-CCP) have been identified as independent risk factors for the development of bone erosion and osteoporosis in rheumatoid arthritis (RA) [14-17]. Similarly, autoantibodies targeting tissue transglutaminase (anti-TTG) have been significantly associated with a higher risk of hip fracture and reduced BMD levels in celiac disease $[18,19]$. Moreover, anti-nuclear autoantibodies (ANAs) have been implicated in reduced BMD in systemic lupus erythematosus (SLE) populations [20]. These findings were however not confirmed by all studies [21, 22].

Notably, many of the studies attempting to characterise the relationship between autoantibodies and bone mass have been conducted in clinical populations with autoimmune conditions [15-28], where there are confounding effects of immunomodulatory drugs such as steroids, which are themselves implicated in pathologic bone loss. Studies examining the usefulness of autoantibodies as a method of screening the general population for osteoporosis are few and contradictory. Our literature review identified a single study utilising middle-aged women drawn from the general population that failed to verify previous findings that autoantibodies against osteoprotegerin (OPG) correlate with BMD [29]. Alternatively, studies comprising samples without any gastrointestinal symptoms of celiac disease, villous atrophy, or evidence of malabsorption reported significant associations between low BMD and increased circulating concentrations of autoantibodies against TTG and EMA (anti endomysial autoantibodies) [23-25]. Furthermore, the clinical utility of autoantibodies in relation to monitoring BMD variability remains an important research question on account of the increasing body of research. Studies utilising clinically autoimmune samples reporting observations of a significant association between a range of autoantibodies and BMD remain important observations given these associations remained significant even after adjusting for age, gender, body mass index (BMI), vitamin D, and smoking habits, all important mediators of bone mass [17]. Moreover, studies utilising early arthritis patients prior to the clinical onset of disease and before the start of treatment have further demonstrated a potential role for autoantibodies in mediating bone health through observations of significant associations between autoantibodies such as anti-CCP and anti-RF and decreased BMD independent of disease activity, specifically inflammatory status [26-28]. Furthermore, animal models have documented the ability of autoantibodies to directly upregulate bone resorption, providing compelling support for a causative role of these antibodies in pathologic bone loss [30-32].

Quantitative ultrasound (QUS) is a noninvasive ultrasound-based technique useful in assessing bone structure (elasticity and microarchitecture) as well as bone mass, therefore providing determinations of bone quality beyond those associated with the dual-energy X-ray absorptiometry (DEXA) [33]. The latter technique is currently considered the gold standard and comprises an accurate technique used to measure BMD at specific fracture-related sites, namely, the spine, hip, and radius [33]. Recently, research has acknowledged the role of bone microarchitecture and elasticity in conjunction with bone density in the development of bone fragility and subsequent fractures, in turn highlighting the important contribution of the QUS measurements [34]. The widespread interest in QUS as a useful measurement tool is also increasingly attributed to it being a rapid, portable, and radiation-free technique making it a more suitable alternative to DEXA for screening a large sample of relatively healthy elderly subjects [35-42]. Additionally, QUS measurements of bone property have been illustrated to correlate with real and volumetric BMD measured by DEXA [37, 38, 40, 42-48]. In this study, we shall take advantage of heel QUS to assess bone properties of our healthy elderly sample.

Age is an important risk factor for autoimmunity, with several autoimmune diseases preferentially occurring more prevalently in the second half of adulthood [49, 50]. Moreover, several studies have reported a higher prevalence of both organ and non-organ-specific autoantibodies amongst the elderly even in the absence of autoimmune disease when compared to the general population [49]. Of particular interest is the fact that the elderly represent a population characterised by high levels of autoantibodies that do not necessarily reflect clinical autoimmune disease [50]. We were therefore able to take advantage of the latter characteristic to evaluate the association between autoantibodies and bone mass in a population without clinical autoimmune disease in order to eliminate the confounding effect of immunomodulatory drugs. 
Osteoporosis is one of the most prominent worldwide public health problems, and morbidity is increasing with the ageing global population [51]. As a silent disease without obvious symptoms and evidence until fracture, early diagnosis remains the key strategy to enable efficient management of this condition. Research has successfully demonstrated the benefits associated with early diagnosis and subsequent intervention on the delayed progression of the disease as well as improved outcomes [52]. Therefore, searching out biomarkers that are able to identify individuals at high risk of developing osteoporosis particularly at a time when BMD measurements of DEXA or QUS do not offer enough information to make a diagnosis would prove particularly useful.

\section{Materials and Methods}

2.1. Ethical Statement. This research was approved by the Human Research Ethics Committees of the Hunter New England Health District and the University of Newcastle $(03 / 12 / 10 / 3.26)$.

2.2. Population. Participants were drawn from the Hunter Community Study (HCS), a longitudinal study comprising a cohort of 3318 community-dwelling Australians aged 55-85 years, randomly selected from the New South Wales (NSW) electoral roll. The specifics of their recruitment and characteristics have previously been described [53].

Individuals with clinical autoimmune disorders were excluded from this analysis (Table 1). These exclusions were instituted to investigate the link between autoantibody and bone mass in a nonclinical sample in order to eliminate the confounding effect of immunomodulatory medications associated with pathologic bone loss. Study participants with osteoporosis were additionally excluded from this analysis.

2.3. Data Collection. At baseline, study participants completed a range of postal questionnaires covering a wide range of data such as medical history, smoking habits, medication use, and dietary habits. Self-report questionnaires were returned by participants when they attended the HCS data collection clinic during which time blood samples were collected and included plasma, serum, whole blood, and DNA that was stored at 80 degrees Celsius in $1 \mathrm{~mL}$ aliquots to minimize freeze-thaw cycles. Additional clinical measures obtained at the data collection center included BMI, level of physical activity, and QUS measurements. Study participants also consented to the linkage of their HCS study data to local and national information databases and records (Table 2). Linking of HCS data to these databases provided a range of detailed information including data on the use of prescription medication.

2.4. Autoantibody Measurements. Serum autoantibody titres were determined using a variety of assays.

(i) HEp-2 ANA slides supplied by Kallestad (Bio-Rad Laboratories) were used to measure anti-nuclear autoantibody (ANA) titre. Negative, borderline, and positive categories corresponded to titres $<1: 40$, $1: 40 \geq$ titres $\leq 1: 80$, and titres $\geq 1: 160$, respectively.
TABle 1: Autoimmune conditions and chronic diseases for exclusion.

\begin{tabular}{l} 
ANA related \\
Lupus, SLE \\
Sjogren's syndrome \\
Scleroderma, CREST \\
Myositis: polymyositis, dermatomyositis \\
Autoimmune liver disease \\
Primary biliary cirrhosis \\
Polyarteritis nodosa \\
Cancer now (malignancy in last 5 years approximately) \\
Cancer ever (only melanoma included from skin cancers) \\
(Active) chronic infection (hepatitis A, hepatitis C) \\
ANCA related \\
Vasculitis \\
Wegener's \\
Churg-Strauss \\
Polyangiitis: microscopic polyangiitis, granulomatosis polyangiitis, \\
eosinophilic granulomatosis with polyangitis colitis \\
IBD: inflammatory bowel disease (not irritable bowel syndrome: IBS) \\
ACGA related \\
Antiphosholipid syndrome \\
Lupus inhibitor \\
$R H F / C C P$-A $b$ related \\
Rheumatoid arthritis \\
Psoriatic arthritis \\
Ankylosing spondylitis \\
TTG-Ab related \\
Celiac disease \\
TPO-Ab related \\
Thyroid disease: Grave's disease, Hashimoto's disease \\
Chronic infections \\
Glandular fever \\
Ross river virus \\
Malaria \\
Dengue \\
\hline
\end{tabular}

TABLE 2: Local and national health information databases linked to hunter community study data.

(i) Hunter New England Area Allied Health Records

(ii) Hunter New England Area Health Service Community Service Records

(iii) Hunter New England Area Health Service Outpatient Records

(iv) Hunter New England Area Health Service Hospital Admission Records

(v) Hunter New England Area Heart and Stroke Register and Diabetes Register

(vi) New South Wales Cancer Registry

(vii) Medicare Australia and Pharmaceutical Benefits Scheme 
(a) Individuals classified as borderline or positive for ANA were subsequently tested for extractable nuclear antigen antibodies (ENA) using an enzyme-linked immunosorbent assay (ELISA). Samples were screened for 6 antigens, namely, anti-Smith (Sm), ribonucleoprotein (RNP), Sjogren's syndrome A and B (SSA and SSB), topoisomerase I (SCL-70), and autoantibodies against amino acyl-tRNA synthetases (Jo-1) (ImmunoConcepts, USA). Individuals who tested positive for ENA but had no defined antigen specificity identified were classified as borderline for ENA, whilst those who had at least one of the six antibody specificities identified were classified as positive.

(ii) Commercial formalin-fixed neutrophil slides (INOVA Diagnostics Inc., San Diego, California) were used to measure anti-neutrophil cytoplasmic antibodies (ANCA). Indeterminate and atypical ANCA was categorised as borderline whilst those staining with a cytoplasmic fluorescence of classical cytoplasmic or perinuclear pattern of $1: 10$ or higher dilution were classified as positive.

(iii) ELISA (Aesku, Germany) was used to test for thyroid peroxidase (TPO) autoantibody titres. Titres $\geq 50 \mathrm{u}-$ nits per millilitre (units $/ \mathrm{mL}$ ) were deemed positive.

(iv) AESKULISA CeliCheck immunoglobulin A (IgA) and immunoglobulin G (IgG) tissue transglutaminase (TTG) ELISA (six-point calibrator) was used to measure TTG autoantibody titres where titre$\mathrm{s} \geq 25$ units $/ \mathrm{mL}$ were considered positive.

(v) ELISA produced by Medical Innovations (fourpoint calibrator curve) was used to test for anticardiolipin antibodies (ACGA). Titres $\leq 5$ IgG phospholipid units (GPL) were defined as negative whilst 6-20 GPL was low positive, 21-40 GPL moderate positive, and over $40 \mathrm{GPL}$ high positive.

(vi) Rheumatoid factor (RHF) was measured using the RHF Beckman Coulter Immage Immunochemistry system, and titres $\geq 20$ international unit per millilitre $(\mathrm{IU} / \mathrm{mL})$ were defined as positive.

(vii) Anti-cyclic citrullinated peptide antibodies (antiCCP) were measured using an anti-CCP2 kit QUANTA lite (INOVA Diagnostics Inc., San Diego) with titres $>20$ enzyme immunoassay units per millilitre $(\mathrm{EU} / \mathrm{mL})$ defined as positive.

All ELISA were performed on the Grifols Triturus platform (Grifols USA, LLC).

2.5. Outcome Measure. Bone mass was measured at the heel using quantitative ultrasound (QUS) (Sahara Hologic sonometer, Hologic Inc., MA, USA). The calcaneus (heel bone) is a recognized and preferred peripheral site for assessing bone quality because it has high metabolic turnover rate and possesses two lateral surfaces, which facilitate the movement of ultrasound through the bone [54]. The heel bone also contains a large percentage of trabecular bone ( $95 \%)$, which has a high metabolic turnover and a pattern of bone loss similar to the spine [55-57]. Results were expressed as QUS index. The QUS index is a composite parameter derived from the two basic measurements generated by the QUS, that is, the speed of sound (SOS) and the broadband ultrasound attenuation (BUA). Research has shown the QUS index (QUI) to be a more useful determinant of bone health status capable of differentiating subjects with a history of fractures as well as predicting future fracture risk in both men and women as well as discriminating women with low BMD from healthy postmenopausal women [43-46]. In addition, several studies have also reported a strong correlation between QUI obtained from QUS and DEXA measurements [58-60]. The QUS index assesses both dimensional structure and bone strength and therefore has a range of clinical applications.

The instrument was calibrated every morning using a phantom, according to the manufacturer's recommendations to protect the long-term stability of the measurement tool.

2.6. Confounders. Potential confounders were purposefully selected using directed acyclic graphs (DAGs), in combination with discussions with content experts (Figure 1) [61]. These included demographic data (age and gender), clinical measures (BMI), lifestyle factors (smoking status, diet, and physical activity), the use of medications likely to be associated with bone metabolism or risk of falls (antiepileptics, antidepressants, and inhaled steroids), and the use of vitamin $\mathrm{D}$ and calcium in the form of supplements. Vitamin D and calcium are recognized regulators of bone homeostasis [62].

Data on demographic and lifestyle factors such as age, gender, and smoking habits were collected via self-report questionnaires. Data on medications including the use of vitamin $\mathrm{D}$ and calcium was also collected via self-report questionnaires and additionally via linkage to Medicare Australia and Pharmaceutical Benefits Scheme (PBS) that enabled collection of information on prescription drug use. BMI (weight/height ${ }^{2}$; $\mathrm{kg} / \mathrm{m}^{2}$ ) was calculated during the clinical visit using height readings measured with a seca wall-mounted stadiometer and weight readings measured with a digital scale.

Physical activity (PA) was measured using step count. Study participants were required to wear a pedometer for seven consecutive days during waking hours to enable mean daily steps to be calculated. Additionally, nutritional assessment was carried out using the Australian Recommended Food Score (ARFS) [63]. The ARFS was calculated based on national recommendations in the Dietary Guidelines for Australian Adults and the core foods given in the Australian Guide to Healthy Eating (AGHE). Respondents are able to obtain a total of 74 points. As a result of missing data, HCS participants were only able to score a possible total Australian Recommended Food Score (TARFS) of 67 points. The scoring method is described in Table 3. A higher score is indicative of greater diet quality.

2.7. Statistics. The nature of the relationship between our selected autoantibodies and bone mass was determined using 


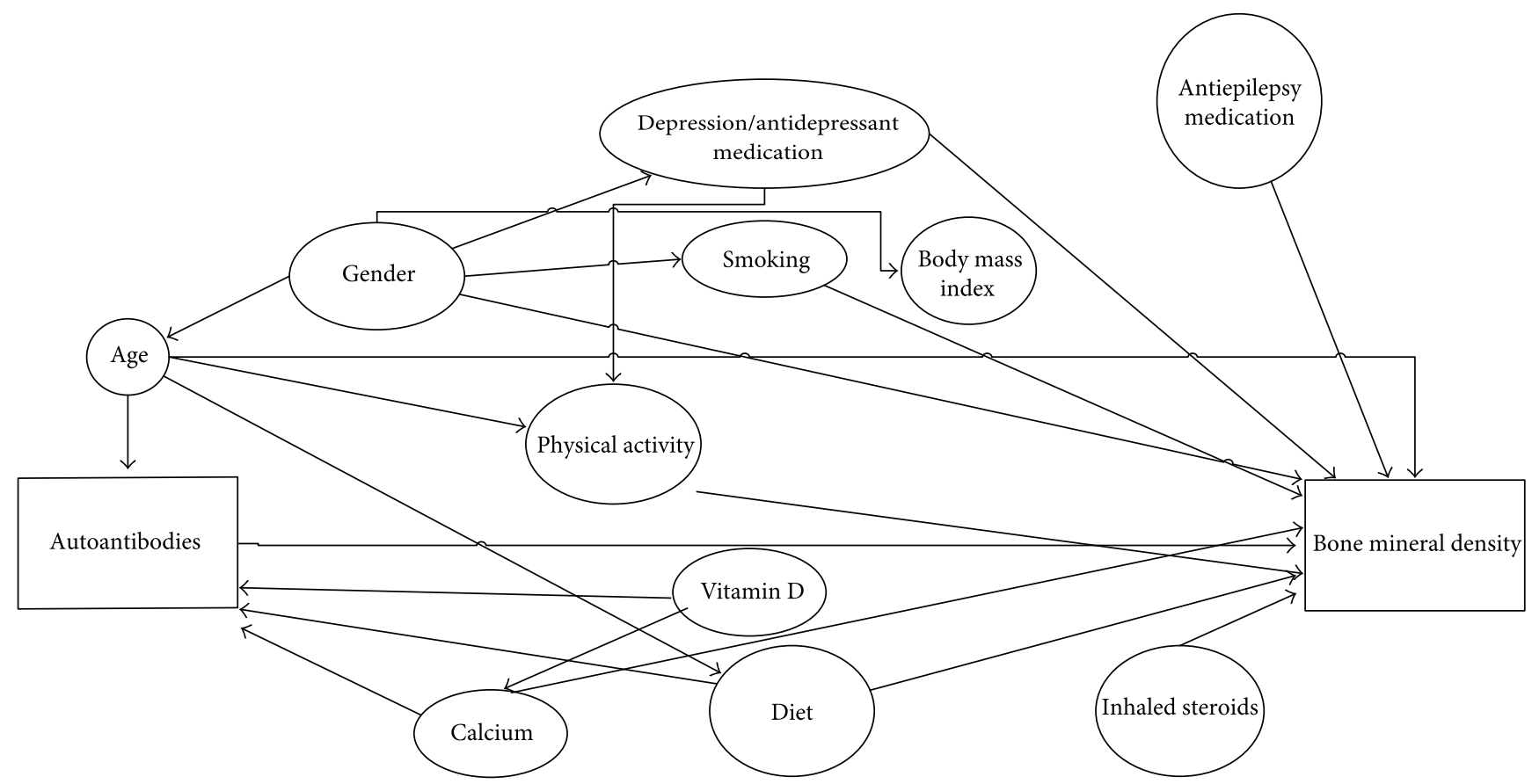

FIGURE 1: Directed acyclic graphs: determining confounding variables.

TABLE 3: Scoring method for foods listed in HCS DQESv2.

\begin{tabular}{|c|c|c|}
\hline Food group & Items awarded 1 point & ARFS \\
\hline Vegetables & $\begin{array}{l}>4 \text { vegetables per day; potatoes cooked without fat; tomatoes fresh/canned; lettuce/endive/salad greens; } \\
\text { carrots; cabbage/brussels sprouts; cauliflower; broccoli; celery; silver beet or spinach; peas; green beans; bean } \\
\text { sprout or alfalfa sprout; pumpkin; onion or leeks; sweet corn; sweet potato; coleslaw; mushrooms; zucchini }\end{array}$ & 20 \\
\hline Fruits & $\begin{array}{l}2 \text { pieces of fruit/day; 1/week of each of fruit or vegetable juice; canned or frozen fruit; oranges or other } \\
\text { citrus; apples; pears; bananas; melons (water, rock, honeydew); pineapple; strawberries; apricots; } \\
\text { peach/nectarines; mango/pawpaw; avocado }\end{array}$ & 14 \\
\hline Protein foods & $\begin{array}{l}\text { Nuts; peanut butter or peanut paste; } 1-4 / \text { week of each of beef, lamb, pork, chicken, fish (steamed, baked, } \\
\text { or grilled fish/canned (salmon, tuna, sardines)); } \geq 1 \text { /week of each of baked beans, soya beans/soy } \\
\text { beans and tofu; use up to } 2 \text { eggs per week }\end{array}$ & 11 \\
\hline Grains & $\begin{array}{l}\geq 1 \text { /week of each of the following bread types with high fibre, wholemeal; } \geq 4 \text { slices bread per day; } \geq 1 / \text { week } \\
\text { All-Bran, Sultana bran, FibrePlus, Branflakes, Weetbix, VitaBrits, Weeties; rice; pasta/noodles }\end{array}$ & 12 \\
\hline Dairy & $\begin{array}{c}\text { Reduced fat or skim; } 500 \mathrm{~mL} / \text { day; cheese } 1 \text { /week; ice-cream; yoghurt 1/week; use ricotta/cottage cheese; } \\
\text { use low-fat cheese }\end{array}$ & 7 \\
\hline Fats & Use nil/polyunsaturated/monounsaturated margarine & 1 \\
\hline Alcohol & Drink beer/wine/spirits 1 /month up to 4 days/week; or 2 glasses maximum/day & 2 \\
\hline
\end{tabular}

linear regression models. Four linear regression models were developed for each of our autoantibodies. The association between each autoimmune marker and QUS index was initially examined alone. Thereafter, we included other factors known to influence bone mineral density to each autoantibody model:

(i) Autoantibody alone (model 1)

(ii) Autoantibody alone run separately for male and female gender (model $2 \mathrm{a}$ and $2 \mathrm{~b}$ )

(iii) Autoantibody + age (model 3) (iv) Autoantibody + age + gender + smoking class + BMI + TARFS + vitamin D + calcium (model 4$)$

(v) Autoantibody + age + gender + smoking class + BMI + TARFS + vitamin D + calcium + physical activity + antidepressants + inhaled steroids + antiepileptics (model 5)

Given that there was no statistically significant association with either physical activity, antidepressants, inhaled steroids, or antiepileptic medication use and QUS index in univariate regression, these variables were only added in sensitivity analysis. We additionally examined the impact on 
bone of expressing more than one autoantibody. All analyses were performed in Stata software v11 [64]. Results are expressed as coefficients with corresponding 95\% confidence intervals and $p$ values. Significance was set at $p<0.05$.

\section{Results}

3.1. Characteristics of Study Participants and Association with Bone Mineral Density. There was a total of 2812 study participants included in this study following the exclusion of persons with clinical autoimmune disease $(n=445)$ and osteoporosis $(n=61)$. Amongst these participants in the community-dwelling sample, 1246 (44\%) were male, median age was 65 years, mean total Australian Recommended Food Score (ARFS) was approximately 28/67, and median step count was 6534.25 per day. Notably, the majority of our sample were overweight $(n=1151 ; 40.93 \%)$ and had never smoked ( $n=1432 ; 50.92 \%)$. Additionally, 309 (11\%) and $47(2 \%)$ study participants were noted to be using calcium and vitamin $\mathrm{D}$ supplements, respectively, according to self report and linkage data. Other demographic and diseaserelated characteristics are presented in Table 4.

Table 5 describes the coefficients for the univariate linear regression analysis (using available cases) for our selected covariates in relation to QUS index. As expected, QUS index was significantly associated with age, gender, smoking, BMI, diet (TARFS), vitamin $\mathrm{D}$, and calcium intake. The results indicated that QUS index was significantly different for males compared to their female counterparts, for individuals who had never smoked compared to past and current smokers, for individuals with a BMI of overweight and obese compared to those in the normal BMI category, and for individuals who were on vitamin $\mathrm{D}$ and calcium supplements compared to those who were not.

Linear regression established that a 1-year increase in age elicited a 0.01 decrease in QUS index $(p=0.006$; 95\% CI: $-0.02-0.004)$. Males demonstrated a QUS index of 0.32 units higher than females $(p=0.000 ; 95 \%$ CI: 0.20-0.44). When compared to normal BMI, being underweight resulted in a QUS index of 0.59 units lower than individuals with a normal BMI (95\% CI: $-1.52-0.34 ; p=0.215)$; however, this association failed to reach significance. Alternatively, a BMI of "overweight" and "obese" significantly increased QUS index by 0.33 and 0.48 , respectively ( $p=0.000$; 95\% CI: $0.17-0.49$; 95\% CI: $0.31-0.65$, resp.). Similarly, past smokers had an increase in QUS index by 0.13 at borderline significance ( $p=0.050 ; 95 \% \mathrm{CI}: 0-0.26)$, whilst current smokers had a significantly decreased QUS index by 0.36 ( $p=0.003 ; 95 \%$ CI: -0.60 to -0.12 ) compared to "never smokers." Dietary intake was also positively correlated with QUS index $(r=$ 0.01 ; 95\% CI: $0.00-0.02 ; p=0.034)$. Unusually, taking vitamin D and calcium supplements negatively correlated with QUS index $(r=-0.59 ; 95 \% \mathrm{CI}:-1.098$ to $-0.073 ; p=0.025$ and $r=-0.35 ; 95 \% \mathrm{CI}:-0.55$ to $-0.15 ; p=0.001$, resp.). Moreover, increasing physical activity by 1000 steps had a negligible effect on QUS index ( $r=0.00$; 95\% CI: $0.00-0.00$; $p=0.285)$. Also, whilst the use of antidepressants increased QUS index by 0.07, inhaled steroid use and antiepileptics decreased QUS index by 0.15 and 0.55 , respectively. Neither
TABLE 4: Baseline demographic and disease-related characteristics of study population, total $(n=2812)$.

\begin{tabular}{|c|c|}
\hline Descriptive characteristics & $\begin{array}{c}\text { Median (IQR); } n(\%) ; \\
\text { mean (SD) }\end{array}$ \\
\hline${ }^{*}$ Age (years)—median (IQR) & $65(55-85)$ \\
\hline Male gender $-n(\%)$ & $1246(44.31 \%)$ \\
\hline${ }^{*} \mathrm{PA}$ (step count)-median (IQR) & $6534.25(4414.63-8572.75)$ \\
\hline TARFS-mean (SD) & $27.9627( \pm 8.02231)$ \\
\hline Antidepressant $-n(\%)$ & $257(9.14 \%)$ \\
\hline Inhaled steroids $-n(\%)$ & $127(4.52 \%)$ \\
\hline Antiepileptics- $n(\%)$ & $24(0.85 \%)$ \\
\hline Calcium-n $(\%)$ & $309(10.99 \%)$ \\
\hline Vitamin $\mathrm{D}-n(\%)$ & $47(1.67 \%)$ \\
\hline (i) Smoking class "never" $-n(\%)$ & $1432(50.92 \%)$ \\
\hline (ii) Smoking class "ever" $-n(\%)$ & $1021(36.31 \%)$ \\
\hline (iii) Smoking class "now" $-n(\%)$ & $211(7.50 \%)$ \\
\hline $\begin{array}{l}\text { (a) } \mathrm{BMI}<18.5 \\
\text { "underweight" }-n(\%)\end{array}$ & $16(0.57 \%)$ \\
\hline $\begin{array}{l}\text { (b) } 18.5 \leq \mathrm{BMI}<25 \\
\text { "normal" }-n(\%)\end{array}$ & $548(19.49 \%)$ \\
\hline $\begin{array}{l}\text { (c) } 25 \leq \text { BMI < 30 } \\
\text { "overweight" }-n(\%)\end{array}$ & $1151(40.93 \%)$ \\
\hline (d) $\mathrm{BMI} \geq 30$ "obese" $-n$ (\%) & $863(30.69 \%)$ \\
\hline
\end{tabular}

Categorical data is presented as frequencies and proportions in brackets. Where continuous data is not normally distributed data is presented as medians with interquartile ranges included in brackets. * indicates data that is not normally distributed. Where data is normally distributed, means and standard deviations are presented. IQR: interquartile range; BMI: body mass index; PA: physical activity; TARFS: Total Australian Recommended Food Score.

TABle 5: Effect of covariates on QUS index.

\begin{tabular}{|c|c|c|c|}
\hline Variable & Coefficient & $\begin{array}{l}\text { 95\% confidence } \\
\text { interval }\end{array}$ & $p$ \\
\hline Age & -0.01 & $-0.02 ;-0.004$ & 0.006 \\
\hline Gender & 0.32 & $0.20 ; 0.44$ & 0.000 \\
\hline PA (step count) & 0.00 & $0.00 ; 0.00$ & 0.285 \\
\hline TARFS & 0.01 & $0.00 ; 0.02$ & 0.034 \\
\hline Antidepressants & 0.06 & $-0.15 ; 0.27$ & 0.582 \\
\hline Inhaled steroids & -0.16 & $-0.47 ; 0.15$ & 0.304 \\
\hline Antiepileptics & -0.57 & $-1.33 ; 0.19$ & 0.145 \\
\hline Vitamin D & -0.59 & $-1.098 ;-0.073$ & 0.025 \\
\hline Calcium & -0.35 & $-0.55 ;-0.15$ & 0.001 \\
\hline Smoking class "ever" & 0.13 & $0.00 ; 0.26$ & 0.050 \\
\hline Smoking class "never" & Ref & - & - \\
\hline Smoking class "now" & -0.36 & $-0.60 ;-0.12$ & 0.003 \\
\hline $\begin{array}{l}\mathrm{BMI}<18.5 \\
\text { "underweight" }\end{array}$ & -0.59 & $-1.52 ; 0.34$ & 0.215 \\
\hline $\begin{array}{l}18.5 \leq \mathrm{BMI}<25 \\
\text { "normal" }\end{array}$ & Ref & - & - \\
\hline $\begin{array}{l}25 \leq \mathrm{BMI}<30 \\
\text { "overweight" }\end{array}$ & 0.33 & $0.17 ; 0.49$ & 0.000 \\
\hline BMI $\geq 30$ "obese" & 0.48 & $0.31 ; 0.65$ & 0.000 \\
\hline
\end{tabular}

PA: physical activity; TARFS: Total Australian Recommended Food Score. 
of the latter medications were significantly associated with QUS index.

3.2. Autoantibody Prevalence. Autoantibody categories (borderline, positive, and negative) were defined based on healthy samples. Autoantibody prevalence varied across our sample. ANA prevalence was highest amongst our sample with approximately $17 \%(316 / 1850)$ found to be positive and $36 \%(669 / 1850)$ borderline for this autoantibody. More female study participants $(172 / 850 ; 20 \%)$ were positive for ANA than their male counterparts (144/996; 14\%). In 979 sera deemed to be positive or borderline for ANA that were subsequently tested for ENA, only 3\% were positive with at least one of 6 specific ENA autoantibody specificities identified. Similar to ANA, more female study participants (17/ $501 ; 3 \%)$ were positive for ENA than their male counterparts (10/477; 2\%). Autoantibodies to TTG, TPO, RHF, CCP, and ACGA were observed in 6\% (119/1850), 9\% (160/1848), $1 \%$ (19/1660), $4 \%(8 / 188)$, and $12 \%(223 / 1830)$ of our sample, respectively. Autoantibodies to CCP, TTG, and cardiolipin were the only ones to present more prevalently amongst males when compared to their female counterparts. AntiRHF was the least prevalent autoantibody within our sample. Autoantibody prevalence is shown in Table 6.

3.3. Correlations between Quantitative Ultrasound Index (QUS Index) and Biochemical and Clinical Variables. The details of the linear regression analyses examining the association between autoantibodies and QUS index are presented in Tables 7 and 8 . ANA positivity was negatively correlated with QUS index. The latter univariate association showed borderline significance $(r=-0.20$; 95\% CI: $-0.40-0.00$; $p=$ $0.046)$. After adjusting for age, the latter association was observed to be approaching significance; however, statistical significance further diminished with the addition of other covariates. After adjusting for age, those who were ANA positive had an average 0.19 lower QUS index than their negative counterparts $(p=0.058)$. Notably, as we moved from borderline to positive autoantibody categories, a larger decrease in QUS index is observed.

Although not reaching statistical significance, ENA, ANCA, TPO, TTG, CCP, and ACGA autoantibody positivity showed a similar tendency towards lower QUS index in the positive autoantibody categories compared to their negative counterparts. Anti-CCP autoantibodies elicited the largest decrease in QUS index; however, these immune markers were not significantly associated with QUS index $(r=-0.43$; $95 \%$ CI: $-1.51-0.65 ; p=0.437$ ). Notably, anti-RHF positivity was observed to elicit an increase in QUS index compared to negative counterparts in the univariate analysis $(r=0.45$; $95 \%$ CI: $-0.44-1.34 ; p=0.325)$. In general, the pattern across all autoimmune markers was similar; there was a larger effect in the univariate analysis which attenuated in the more adjusted models. Moreover, there was an apparent doseresponse effect on QUS index in moving from negative to borderline to positive immune marker groups. Notably, examination of $R$ squared $\left(R^{2}\right)$ illustrated that the addition of physical activity, antidepressants, inhaled steroids, and antiepileptics did not improve the model (model 5) $\left(R^{2}\right.$ data not shown).

A minority of our sample was positive for more than one autoantibody (Refer to Table 9). The specificities that largely overlapped amongst the coexpression of any two autoantibodies were ANA with TTG, TPO, ACGA, and ANCA as well as TPO and TTG, ACGA and ENA, TPO and TTG, plus ANCA and ENA, TPO, TTG, and ACGA. Sensitivity analyses examining the impact on bone being positive for more than one autoantibody yielded some significant results. Individuals who were positive for both ANCA and ACGA suffered a QUS index 0.84 less than their negative counterparts (95\% CI: -1.53 to $-0.15 ; p=0.017$ ) whilst individuals who were positive for TPO and TTG suffered a QUS index 0.85 less than their negative counterparts (95\% CI: -1.63 to $-0.06 ; p=0.036$ ). Even fewer individuals were positive for more than two autoantibodies, and the coexpression of three autoantibodies did not yield any significant correlation with QUS index.

\section{Discussion}

Despite existing literature pointing to a potential role of autoantibodies in modulating bone mass, it remains a relatively underresearched subject matter. Notably, the majority of existing research has investigated the relationship between autoantibodies and QUS using samples with clinical autoimmune disease [14-28]. Our results failed to observe any significant association between most of our autoimmune markers and QUS index. Nonetheless, this study provides novel data towards efforts aimed at ascertaining the potential role of autoantibodies in pathogenic bone loss. The results are particularly important, as our study comprised an elderly population sample with no clinical autoimmune disease, thus eliminating the influence of a range of immunomodulatory drugs on our observed outcomes. Moreover, we found only one study investigating the association between autoantibodies and bone utilizing QUS parameters amongst a healthy population sample [65]. Additionally, our findings also contribute to data examining the association between a range of anthropometric measurements and QUS index of the calcaneus amongst an elderly sample.

Although BMD obtained by DEXA is a standard diagnostic technique for osteoporosis, it is difficult to apply in community-based studies because of a lack of portability, high costs, and exposure to ionizing radiation [66]. At present, the QUS has generated widespread interest particularly as a population screening tool as it gives a quick evaluation of bone that is reportedly highly correlated with DEXA measurement of $\mathrm{BMD}$, it is inexpensive and easy to carry, and it estimates the bone density of the calcaneus whilst also providing some information concerning the structural organization of the bone [66-69]. The QUS therefore improves accessibility to testing particularly amongst patients with restricted mobility.

Our results revealed a significant association between our QUS parameter and age, gender, BMI, smoking habits, and diet as well as vitamin D and calcium intake. These observations coincide with previous reports, where BMD was 


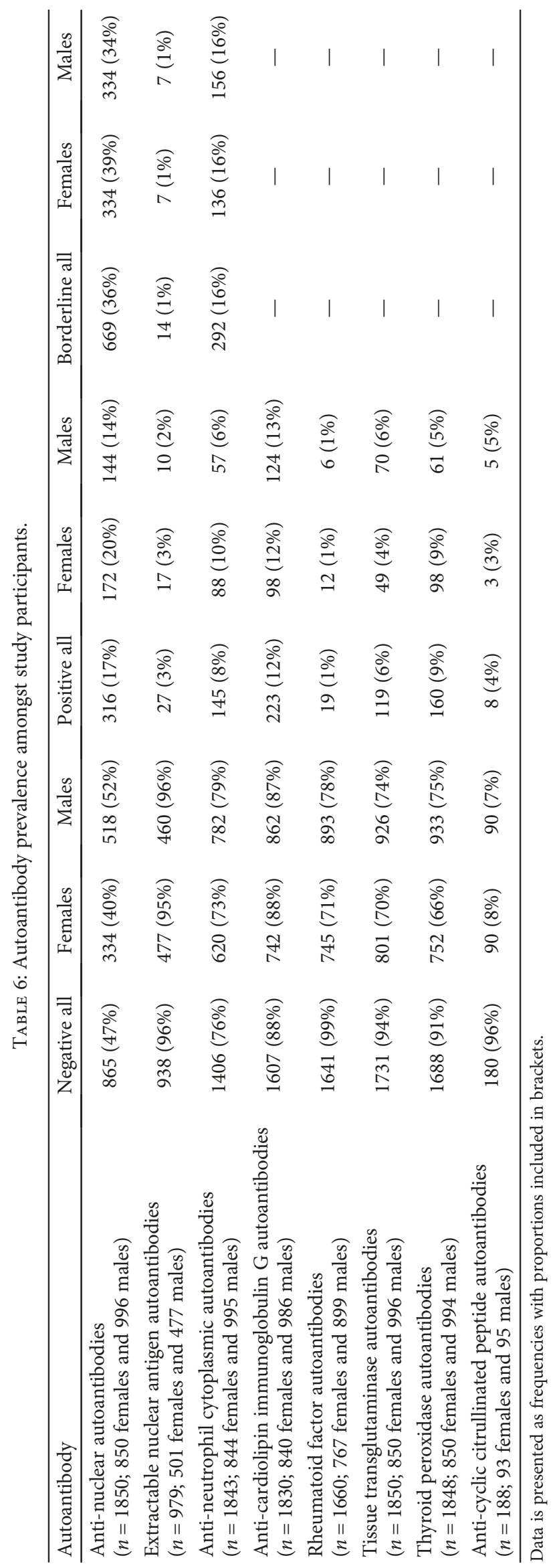


TABLE 7: Correlation between autoantibodies and quantitative ultrasound index (QUS index): univariate analysis.

\begin{tabular}{|c|c|c|c|}
\hline Autoantibody & $\begin{array}{c}\text { Model } 1 \\
\text { (autoantibody alone) } \\
\text { [coefficient; (95\% CI); } p \text { value] }\end{array}$ & $\begin{array}{l}\text { Model 2a } \\
\text { (autoantibody alone, females only) } \\
\text { [coefficient; (95\% CI); } p \text { value] }\end{array}$ & $\begin{array}{c}\text { Model } 2 \mathrm{~b} \\
\text { (autoantibody alone, males only) } \\
\text { [coefficient; (95\% CI); } p \text { value] }\end{array}$ \\
\hline \multirow{4}{*}{ ANA borderline } & -0.11 & -0.18 & -0.13 \\
\hline & $(-0.26 ; 0.05)$ & $(-0.22 ; 0.18)$ & $(-0.36 ; 0.10)$ \\
\hline & $p=0.168$ & $p=0.857$ & $p=0.267$ \\
\hline & $n=1628$ & $n=749$ & $n=879$ \\
\hline \multirow{4}{*}{ ANA positive } & -0.20 & -0.15 & -0.16 \\
\hline & $(-0.40 ; 0.00)$ & $(-0.40 ; 0.09)$ & $(-0.47 ; 0.15)$ \\
\hline & $p=0.046$ & $p=0.228$ & $p=0.304$ \\
\hline & $n=1628$ & $n=749$ & $n=879$ \\
\hline \multirow{4}{*}{$\begin{array}{l}\text { Anti-ENA autoantibodies } \\
\text { borderline }\end{array}$} & 0.55 & 0.80 & 0.27 \\
\hline & $(-0.38 ; 1.49)$ & $(-0.25 ; 1.84)$ & $(-1.38 ; 1.91)$ \\
\hline & $p=0.245$ & $p=0.135$ & $p=0.749$ \\
\hline & $n=877$ & $n=442$ & $n=435$ \\
\hline \multirow{4}{*}{ Anti-ENA autoantibodies positive } & -0.39 & -0.21 & -0.59 \\
\hline & $(-0.99 ; 0.20)$ & $(-0.86 ; 0.43)$ & $(-1.70 ; 0.51)$ \\
\hline & $p=0.194$ & $p=0.516$ & $p=0.291$ \\
\hline & $n=877$ & $n=442$ & $n=435$ \\
\hline \multirow{4}{*}{ ANCA borderline } & -0.02 & -0.04 & 0.01 \\
\hline & $(-0.21 ; 0.18)$ & $(-0.29 ; 0.21)$ & $(-0.27 ; 0.30)$ \\
\hline & $p=0.868$ & $p=0.744$ & $p=0.922$ \\
\hline & $n=1621$ & $n=743$ & $n=878$ \\
\hline \multirow{4}{*}{ ANCA positive } & -0.19 & 0.12 & -0.50 \\
\hline & $(-0.45 ; 0.07)$ & $(-0.18 ; 0.42)$ & $(-0.93 ;-0.05)$ \\
\hline & $p=0.160$ & $p=0.441$ & $p=0.028$ \\
\hline & $n=1621$ & $n=743$ & $n=878$ \\
\hline \multirow{4}{*}{ Anti-TPO autoantibodies positive } & -0.21 & -0.18 & -0.11 \\
\hline & $(-0.46 ; 0.04)$ & $(-0.47 ; 0.10)$ & $(-0.55 ; 0.33)$ \\
\hline & $p=0.100$ & $p=0.201$ & $p=0.618$ \\
\hline & $n=2114$ & $n=1011$ & $n=1099$ \\
\hline \multirow{4}{*}{ Anti-RHF autoantibodies positive } & 0.45 & 0.31 & 0.76 \\
\hline & $(-0.44 ; 1.34)$ & $(-0.68 ; 1.30)$ & $(-0.80 ; 2.32)$ \\
\hline & $p=0.325$ & $p=0.536$ & $p=0.338$ \\
\hline & $n=1947$ & $n=931$ & $n=1012$ \\
\hline \multirow{4}{*}{ Anti-TTG autoantibodies positive } & -0.15 & -0.02 & -0.28 \\
\hline & $(-0.44 ; 0.14)$ & $(-0.42 ; 0.37)$ & $(-0.69 ; 0.14)$ \\
\hline & $p=0.306$ & $p=0.902$ & $p=0.192$ \\
\hline & $n=2114$ & $n=1011$ & $n=1099$ \\
\hline \multirow{4}{*}{ Anti-CCP autoantibodies positive } & -043 & -0.39 & -0.61 \\
\hline & $(-1.51 ; 0.65)$ & $(-2.11 ; 1.33)$ & $(-2.03 ; 0.81)$ \\
\hline & $p=0.437$ & $p=0.658$ & $p=0.400$ \\
\hline & $n=2114$ & $n=1011$ & $n=1099$ \\
\hline
\end{tabular}


TABLe 7: Continued.

\begin{tabular}{lccc}
\hline Autoantibody & $\begin{array}{c}\text { Model 1 } \\
\text { (autoantibody alone) } \\
\text { [coefficient; (95\% CI); } p \text { value] }\end{array}$ & $\begin{array}{c}\text { Model 2a } \\
\text { (autoantibody alone, females only) } \\
\text { [coefficient; (95\% CI); } p \text { value] }\end{array}$ & $\begin{array}{c}\text { Model 2b } \\
\text { (autoantibody alone, males only) } \\
\text { [coefficient; (95\% CI); } p \text { value] }\end{array}$ \\
\hline ACGA positive & -0.02 & -0.10 & -0.04 \\
$(-0.23 ; 0.20)$ & $(-0.38 ; 0.18)$ & $(-0.27 ; 0.35)$ \\
& $p=0.887$ & $p=0.480$ & $n=0.804$ \\
\hline
\end{tabular}

Data presented in bold represents significant results. Data presented in italics represents results approaching significance. $95 \%$ CI: $95 \%$ confidence interval; Ref: reference; ANA: anti-nuclear autoantibodies; Anti-ENA autoantibodies: anti-extractable nuclear antigen autoantibodies; ANCA: anti-neutrophil cytoplasmic autoantibodies; Anti-TPO: anti-thyroid peroxidase autoantibodies; Anti-RHF: anti-rheumatoid factor autoantibodies; Anti-TTG: anti-tissue transglutaminase autoantibodies; Anti-CCP: anti-cyclic citrullinated peptide autoantibodies; ACGA: anti-cardiolipin immunoglobulin G autoantibodies; BMI: body mass index; PA: physical activity; TARFS: Total Australian Recommended Food Score.

observed to be significantly associated with age, gender, BMI, and smoking habits [54, 70-72]. In fact, QUS variables have been acknowledged to decline with age similar to DEXA BMD measurements [73-75]. Our results confirmed the latter observation. Age-related bone loss is largely attributed to a rapid decline in sex hormones implicated in bone loss in varying amounts across both genders $[71,74,76]$.

Gender as expected was positively associated with QUS index as you moved from female to male gender $(r=0.32$; 95\% CI: 0.20-0.44; $p=0.000$ ). Gender-dependent differences in bone mass have been observed in both children and adults, with males reported to have a higher BMD than their female counterparts [77]. Similar gender-specific differences in QUS parameters have also been made evident by existing research $[38,54,78,79]$. Gender-dependent differences in bone mass are linked to age-related decreases in sex hormones and differences in peak bone mass attained $[74,76]$. Female gender is a well established risk factor for osteoporosis [80]. This is largely attributed to the role of sex hormones and sex hormone globulin that correlate with loss of BMD, fracture risk, and bone turnover [74, 76]. Additionally, gender differences in osteoporosis must be understood in the context of the physiology of bone maturation and skeletal growth as well as variations in anthropometric measures such as BMI between male and female genders [54, 80]. Briefly, males are acknowledged to achieve similar or higher bone density than females and at a later age [80]. Additionally, though gradual loss of bone mass is common across both genders with age, women tend to lose bone at a faster rate than their male counterparts [80]. Moreover, estrogen deficiency which plays a major role in osteoporosis development for both genders is noted to be more pronounced for women and begin at a younger age $[74,76,80]$. Furthermore, males are believed to have higher BMI than females and new research has also highlighted gender-related variations in molecular signaling between bone and muscle independent of purely mechanical interactions that result in gender differences in the acquisition and age-related loss in bone and muscle tissue [70, 71, 81]. Body weight is a known protective factor of bone loss [81]. As was depicted in our results, QUS index amongst individuals who are classified as overweight or obese is higher than those within the normal BMI category, $r=0.33$; 95\% CI: $0.17-0.49 ; p=0.000$ and $r=0.48 ; 95 \%$ CI: $0.31-0.65 ; p=$ 0.000 , respectively. In this regard, a higher body weight is believed to lead to greater mechanical loading of bone with subsequent stimulation of bone formation and an increase in bone density [82]. Indeed, BMI has been reported to positively correlate with QUS index in postmenopausal women as well as in older male and female population samples [83, 84]. QUS index was lower amongst those classified as underweight when compared to normal BMI. This latter association however failed to reach statistical significance, an observation that is likely to have resulted from the small proportion of our sample that was underweight $(n=16)$.

Furthermore, our results coincide with reports of a recent meta-analysis that observed a significantly reduced bone mass amongst smokers compared with nonsmokers at all bone sites [72]. In fact, "current smokers" are observed to be a negative predictor of QUS parameters (BUA, SOS, and QUS index) amongst both men and women in previous studies [85]. Interestingly, autoantibodies have been proposed to mediate the effect of cigarette smoke on bone mass [13]. Notably, "smoking class ever" representing former smokers was significantly and positively associated with QUI in our elderly sample $(r=0.13$; $95 \%$ CI: $0-0.26 ; p=0.05)$. Previous studies using both the Sahara device and other sonometers have provided somewhat discrepant findings with both positive and negative associations reported between QUS parameters and previous smoking habits [86-90].

Diet was observed to positively correlate with QUS index amongst our elderly sample $(r=0.01 ; 95 \%$ CI: $0-0.02 ; p=$ 0.034 ). Our average TARF score (28 out of a possible 67 points) is suggestive of a diet that may not be consistent with consumption of a greater variety of foods as recommended by the Australian Dietary Guidelines [63]. Diet has been identified as an important mediator of osteoporosis risk [91]. In particular, excessive alcohol, caffeine, and tobacco use as well as low calcium and vitamin D are acknowledged to increase the risk of fragility fractures [92]. Inconsistent observations amongst studies investigating the association between diet and bone quality (mass and microarchitecture) in elderly samples have been attributed to differences in methods of measuring nutritional status (i.e., anthropometry and biochemical data versus anthropometry alone) as well as variations in study participant age [92]. Notably, a significant negative correlation was observed between calcium and vitamin D amongst our sample. Both calcium and vitamin D are recognized in existing literature as having a positive effect on 
TABLE 8: Correlation between autoantibodies and quantitative ultrasound index (QUS index) after adjustment for potential confounders.

\begin{tabular}{|c|c|c|c|}
\hline Autoantibody & $\begin{array}{c}\text { Model } 3 \\
\text { (autoantibody + age) } \\
\text { [coefficient; }(95 \% \mathrm{CI}) ; p \text { value }]\end{array}$ & $\begin{array}{c}\text { Model } 4 \\
\text { (autoantibody + age, gender, smoking } \\
\text { class, BMI, TARFS, vitamin D, calcium) } \\
\text { [coefficient; }(95 \% \mathrm{CI}) ; p \text { value] }\end{array}$ & $\begin{array}{c}\text { Model 5 } \\
\text { (autoantibody + age, gender, } \\
\text { smoking class, BMI, TARFS, } \\
\text { vitamin D; calcium; antidepressants, } \\
\text { inhaled steroids, antiepileptics; } \\
\text { physical activity) } \\
\text { [coefficient; (95\% CI); } p \text { value] }\end{array}$ \\
\hline \multirow{4}{*}{ ANA borderline } & -0.10 & -0.09 & 0.027 \\
\hline & $(-0.25 ; 0.06)$ & $(-0.25 ; 0.07)$ & $(-0.17 ; 0.22)$ \\
\hline & $p=0.217$ & $p=0.264$ & $p=0.784$ \\
\hline & $n=1621$ & $n=1467$ & $n=1013$ \\
\hline \multirow{4}{*}{ ANA positive } & -0.19 & -0.11 & 0.07 \\
\hline & $(-0.39 ; 0.01)$ & $(-0.32 ; 0.09)$ & $(-0.18 ; 0.32)$ \\
\hline & $p=0.058$ & $p=0.276$ & $p=0.586$ \\
\hline & $n=1612$ & $n=1467$ & $n=1013$ \\
\hline \multirow{4}{*}{$\begin{array}{l}\text { Anti-ENA } \\
\text { autoantibodies borderline }\end{array}$} & 0.52 & 0.70 & 0.75 \\
\hline & $(-0.41 ; 1.45)$ & $(-0.34 ; 1.73)$ & $(-0.48 ; 1.98)$ \\
\hline & $p=0.274$ & $p=0.186$ & $p=0.232$ \\
\hline & $n=867$ & $n=790$ & $n=549$ \\
\hline \multirow{4}{*}{$\begin{array}{l}\text { Anti-ENA } \\
\text { autoantibodies positive }\end{array}$} & -0.39 & -0.61 & -0.95 \\
\hline & $(-0.98 ; 0.21)$ & $(-1.26 ; 0.03)$ & $(-1.79 ; 0.11)$ \\
\hline & $p=0.201$ & $p=0.062$ & $p=0.027$ \\
\hline & $n=867$ & $n=790$ & $n=549$ \\
\hline \multirow{4}{*}{ NCA borderline } & -0.01 & 0.05 & 0.06 \\
\hline & $(-0.21 ; 0.19)$ & $(-0.15 ; 0.25)$ & $(-0.19 ; 0.30)$ \\
\hline & $p=0.911$ & $p=0.624$ & $p=0.648$ \\
\hline & $n=1610$ & $n=1465$ & $n=1012$ \\
\hline \multirow{4}{*}{ ANCA positive } & -0.17 & -0.10 & 0.12 \\
\hline & $(-0.44 ; 0.07)$ & $(-0.38 ; 0.17)$ & $(-0.23 ; 0.47)$ \\
\hline & $p=0.148$ & $p=0.461$ & $p=0.495$ \\
\hline & $n=1610$ & $n=1465$ & $n=1012$ \\
\hline \multirow{4}{*}{$\begin{array}{l}\text { Anti-TPO } \\
\text { autoantibodies positive }\end{array}$} & -0.19 & -0.15 & 0.035 \\
\hline & $(-0.44 ; 0.07)$ & $(-0.41 ; 0.11)$ & $(-0.31 ; 0.38)$ \\
\hline & $p=0.148$ & $p=0.257$ & $p=0.841$ \\
\hline & $n=1804$ & $n=1640$ & $n=1144$ \\
\hline \multirow{4}{*}{$\begin{array}{l}\text { Anti-RHF autoantibodies } \\
\text { positive }\end{array}$} & -0.14 & -0.11 & -0.09 \\
\hline & $(-0.35 ; 0.79)$ & $(-0.34 ; 0.11)$ & $(-0.35 ; 0.17)$ \\
\hline & $p=0.214$ & $p=0.321$ & $p=0.497$ \\
\hline & $n=1637$ & $n=1486$ & $n=1040$ \\
\hline \multirow{4}{*}{$\begin{array}{l}\text { Anti-TTG } \\
\text { autoantibodies positive }\end{array}$} & -0.15 & -0.21 & -0.23 \\
\hline & $(-0.44 ; 0.14)$ & $(-0.50 ; 0.09)$ & $(-0.60 ; 0.15)$ \\
\hline & $p=0.319$ & $p=0.166$ & $p=0.232$ \\
\hline & $n=1804$ & $n=1640$ & $n=1144$ \\
\hline \multirow{4}{*}{$\begin{array}{l}\text { Anti-CCP autoantibodies } \\
\text { positive }\end{array}$} & -0.45 & -0.65 & -1.36 \\
\hline & $(-1.52 ; 0.63)$ & $(-1.79 ; 0.49)$ & $(-2.76 ; 0.04)$ \\
\hline & $p=0.415$ & $p=0.264$ & $p=0.058$ \\
\hline & $n=1.804$ & $n=1640$ & $n=1144$ \\
\hline
\end{tabular}


TABLE 8: Continued.

\begin{tabular}{|c|c|c|c|}
\hline Autoantibody & $\begin{array}{c}\text { Model } 3 \\
\text { (autoantibody + age) } \\
\text { [coefficient; }(95 \% \mathrm{CI}) ; p \text { value] }\end{array}$ & $\begin{array}{c}\text { Model } 4 \\
\text { (autoantibody }+ \text { age, gender, smoking } \\
\text { class, BMI, TARFS, vitamin D, calcium) } \\
{[\text { coefficient; }(95 \% \mathrm{CI}) ; p \text { value }]}\end{array}$ & $\begin{array}{c}\text { Model } 5 \\
\text { (autoantibody + age, gender, } \\
\text { smoking class, BMI, TARFS, } \\
\text { vitamin D; calcium; antidepressants, } \\
\text { inhaled steroids, antiepileptics; } \\
\text { physical activity) } \\
\text { [coefficient; }(95 \% \mathrm{CI}) ; p \text { value] }\end{array}$ \\
\hline \multirow{4}{*}{ ACGA positive } & -0.02 & -0.05 & -0.098 \\
\hline & $(-0.24 ; 0.19)$ & $(-0.27 ; 0.17)$ & $(-0.35 ; 0.16)$ \\
\hline & $p=0.829$ & $p=0.674$ & $p=0.450$ \\
\hline & $n=1599$ & $n=1454$ & $n=1005$ \\
\hline
\end{tabular}

Data presented in bold represents significant results. Data presented in italics represents results approaching significance. 95\% CI: 95\% confidence interval; Ref: reference; ANA: anti-nuclear autoantibodies; Anti-ENA autoantibodies: anti-extractable nuclear antigen autoantibodies; ANCA: anti-neutrophil cytoplasmic autoantibodies; Anti-TPO: anti-thyroid peroxidase autoantibodies; Anti-RHF: anti-rheumatoid factor autoantibodies; Anti-TTG: anti-tissue transglutaminase autoantibodies; Anti-CCP: anti-cyclic citrullinated peptide autoantibodies; ACGA: anti-cardiolipin immunoglobulin G autoantibodies; BMI: body mass index; PA: physical activity; TARFS: Total Australian Recommended Food Score.

bone health as they are important nutrients for the development, growth, and maintenance of a healthy skeleton throughout life $[93,94]$. Vitamin D and calcium are closely linked through vitamin D's regulatory role of intestinal calcium absorption [93]. Contradictory reports exist describing the relationship between vitamin $\mathrm{D}$, calcium, and bone mass [93-100]. According to existing literature, high dietary calcium intake and not daily calcium supplementation have been reported to enhance bone mass [94]. Moreover, the beneficial effect of calcium on BMD is reportedly only evident in physically active groups $[95,96]$. Additionally, low dietary calcium intake has been linked to increased turnover of vitamin $\mathrm{D}$ metabolites, an observation that is proposed to affect the subsequent relationship between vitamin $\mathrm{D}$ and BMD [97]. Similarly, research has failed to illustrate the effectiveness of vitamin D supplements in increasing BMD [98]. However, a longitudinal study of institutionalized women illustrated a positive effect on quantitative ultrasound of bone of supplementation with vitamin D3 and calcium [100]. Notably, supplementation with vitamin D3 and calcium in the latter study highlighted that only BUA was observed to reflect the positive effect on bone of the latter nutrients [100]. As we lacked dietary vitamin D and calcium data, we were unable to clarify the relationship between these nutrients and QUS index in our study.

Our results failed to show a significant correlation between the use of antiepileptics, antidepressants, or inhaled steroids and QUI. Notably, contrary to previous research indicating that QUS parameters at the heel respond to physical activity, our results show that physical activity had no effect on QUS index [85, 97, 101]. Physical exercise is an acknowledged and important mediator of bone biomechanics [102]. Muscle contraction produces mechanical stress that results in activation of osteoblasts with subsequent bone formation [103]. Exercise is additionally recognized to promote bone mass acquisition through direct mechanical loading effects on bone in addition to muscle contraction [103]. Clear clinical guidelines regarding the most appropriate type, intensity, and duration of activity to prevent bone loss are however lacking. The prevailing general rule regarding exercise and BMD is that exercises that include loading, weight-bearing elements, and muscular strengthening factors are considered to be most appropriate in the context of osteoporosis [103]. Yet not all types of physical activity that provide bone loading to the skeleton have been shown to produce bone mass benefits [97]. There are also activities that provide bone loading at one site of the body but not at other sites [97]. This is based on the premise that osteogenic effects of exercise are specific to the anatomical sites where the mechanical strain occurs [97]. The calcaneus that plays a central position in supporting body weight is considered the skeletal site where maximal ground reaction forces are applied with every heel strike during exercise [94]. Nonetheless, according to a recent meta-analysis that sought to mathematically consolidate research on the effects of walking interventions on BMD in men and women aged 50 years and older, walking has a significant $(p \geq 0.03)$ positive effect on lumbar BMD but not femur or the calcaneus [104]. Moreover, studies that have examined the impact of physical activity on heel ultrasound are faulted for relying on historical self-report of physical activity [104]. On average, our sample walked 6534.25 steps per day. It is also possible that the amount of exercise undertaken by our study participants did not necessarily surpass the threshold necessary for modulating bone mass.

Interestingly, ANA was the most common autoimmune marker and the only autoantibody significantly associated with variability in QUS index in univariate analysis, an observation that was likely due to high power. The latter association was observed to be approaching significance after adjusting for age but disappeared following further adjustment for additional covariates. In particular, ANA was not significantly associated with QUS index when analysis was carried out separately for female and male genders $(r=-$ 0.18 ; 95\% CI: $-0.22-0.18 ; p=0.857$ and $r=-0.13$; 95\% CI: $-0.36-0.10 ; p=0.267$, resp.).

Existing literature has linked ANAs to lower BMD amongst cohorts with clinical autoimmune disease. In particular, anti-deoxyribonucleic acid (DNA) topoisomerase I autoantibodies have been noted to significantly correlate with 
TABLE 9: Association between quantitative ultrasound index (QUS index) and the coexpression of more than one autoantibody (for available cases).

\begin{tabular}{|c|c|c|c|c|}
\hline Autoantibody & Correlation coefficient & $95 \%$ confidence interval & $p$ value & $N$ pos \\
\hline ANA + ENA & -0.67 & $-1.57 ; 0.23$ & 0.144 & $10 / 1625(1 \%)$ \\
\hline ANA + ANCA & -0.12 & $-0.48 ; 0.23$ & 0.497 & $72 / 1628(4 \%)$ \\
\hline $\mathrm{ANA}+\mathrm{TPO}$ & -0.30 & $-0.79 ; 0.19$ & 0.227 & $40 / 1628(2 \%)$ \\
\hline $\mathrm{ANA}+\mathrm{RHF}$ & 1.11 & $-0.53 ; 2.75$ & 0.183 & $5 / 1589(7 \%)$ \\
\hline $\mathrm{ANA}+\mathrm{TTG}$ & -0.35 & $-0.99 ; 0.29$ & 0.283 & $24 / 1628(1 \%)$ \\
\hline ANA + ACGA & -0.04 & $-0.48 ; 0.39$ & 0.850 & $46 / 1626(3 \%)$ \\
\hline ANCA + ENA & -0.22 & $-1.50 ; 1.05$ & 0.729 & $5 / 1619(0.3 \%)$ \\
\hline $\mathrm{ANCA}+\mathrm{TTG}$ & 0.23 & $-0.78 ; 1.23$ & 0.655 & $10 / 1628(1 \%)$ \\
\hline $\mathrm{ANCA}+\mathrm{ACGA}$ & -0.84 & $-1.53 ;-0.15$ & 0.017 & $18 / 1619(1 \%)$ \\
\hline $\mathrm{ANCA}+\mathrm{TPO}$ & -0.38 & $-1.07 ; 0.31$ & 0.283 & $21 / 1627(1 \%)$ \\
\hline $\mathrm{ANCA}+\mathrm{RHF}$ & 1.81 & $-1.03 ; 4.65$ & 0.211 & $2 / 1609(0.1 \%)$ \\
\hline $\mathrm{TPO}+\mathrm{TTG}$ & -0.85 & $-1.63 ;-0.06$ & 0.036 & $15 / 1628(1 \%)$ \\
\hline $\mathrm{TPO}+\mathrm{ACGA}$ & 0.17 & $-0.52 ; 0.87$ & 0.621 & $21 / 1625(1 \%)$ \\
\hline $\mathrm{ANA}+\mathrm{ANCA}+\mathrm{TPO}$ & -0.64 & $-1.50 ; 0.21$ & 0.141 & $12 / 1628(1 \%)$ \\
\hline $\mathrm{ANA}+\mathrm{TPO}+\mathrm{ACGA}$ & -0.37 & $-1.53 ; 0.79$ & 0.533 & $7 / 1627(0.4 \%)$ \\
\hline
\end{tabular}

BMD amongst a sample of Moroccan women with systemic sclerosis [105]. Additionally, anti-centromere autoantibodies have been identified as independent risk factors for bone damage amongst systemic sclerosis patients, whilst high anti-double-stranded DNA (dsDNA) autoantibody levels were observed to independently predict 10 -year risk of incurring a hip fracture amongst SLE patients $[20,106]$. ANAs represent one of the least researched immune markers in relation to pathologic bone loss. To our knowledge, this is the first study examining the association between ANAs and variability in bone mass in the absence of clinical autoimmunity. The production of ANAs is one of the major defining features of SLE, and their presence is part of the clinical diagnostic criteria [107]. Additionally, osteoporosis reportedly occurs in up to $68 \%$ of SLE sufferers [108]. The majority of studies examining the high prevalence of osteoporosis in SLE have however failed to explore the potential role of ANAs in mediating this relationship [108-111]. ANAs target a variety of nuclear antigens such as dsDNA, which are intimately involved in SLE pathogenesis [112]. Their exact mechanism of action in pathologic bone loss however remains unclear.

The direction and magnitude of the association between our autoimmune markers and QUS index were observed to be consistent. However, unlike ANA, the remaining autoantibodies did not reach statistical significance, likely due to the lower prevalence of these immune markers in our nondisease population. The dose-response effect was also reasonably consistent.

In particular, the small proportion of our sample positive for anti-ENA, anti-RHF, and anti-CCP autoantibodies significantly affected the power of our study and subsequently our ability to reliably estimate the association between the latter immune markers and QUS index, based on our results.
RHF was noted to have the lowest prevalence of all autoantibodies measured within our sample. The prevalence of these autoantibodies in the general population has been reported to increase with age $[113,114]$. This increase is largely attributed to the effect of progressive senescence of immune function [114]. However, successfully ageing individuals (individuals lacking autoimmune or chronic disease) have been reported to have a prevalence of RHF which is not statistically significantly higher than a healthy young adult control group [115]. It is possible that the low RHF prevalence noted within our cohort was a result of the relatively good health of this sample.

It is important to note that previous research has illustrated a role for anti-RHF autoantibodies as enhancers of bone loss in the presence of anti-CCP autoantibodies [116]. However, a recent study, whereby radiographic progression in RA patients stratified by anti-CCP and RHF autoantibodies illustrated a more pronounced progression of structural damage associated with the presence of each autoantibody, contradicted these findings [19]. The latter study instead suggests an independent effect of RHF on bone loss in RA [19]. It has been proposed that the latter process is mediated by a proinflammatory environment resulting from activation of monocytes and macrophages through binding of RHF with low affinity $\mathrm{Fc}$ gamma $(\mathrm{Fc} \gamma)$ receptors found on their surface $[13,117,118]$. Furthermore, anti-CCP autoantibodies are acknowledged to bind to a diverse group of modified proteins in which arginine residues have been transformed into citrulline by peptidyl arginine deiminase [119]. However, not all their antigenic targets are implicated in modulating bone homeostasis [14, $120,121]$. At present, research has implicated citrullinated fibrinogen, enolase, and vimentin specificities in mediating bone loss via increased osteoclast resorption [14, 120, 121]. In particular, citrullinated vimentin receptors expressed on 
the surface of osteoclasts and myeloid precursors are highly implicated [14, 120-122]. The latter highlights the potential for these autoantibodies to stimulate differentiation of boneresorbing osteoclasts, as well as trigger osteoclast-driven local bone resorption. Anti-CCP autoantibodies are implicated in early bone loss during the preclinical phase of RA and have been reported to independently predict bone erosion in RA patients independent of measures of disease activity such as the disease activity score for RA(DAS28) and inflammation as measured by levels of C-reactive protein (CRP) [121, 123].

Thyroid dysfunction is acknowledged as having unfavourable effects on the musculoskeletal system $[124,125]$. Individuals with hyperthyroidism, subclinical hyperthyroidism, and hypothyroidism have been repeatedly observed to exhibit an increased fracture risk $[124,125]$. In this regard, the aetiology of thyroid dysfunction is multifactorial and it remains unclear which underlying mechanisms are responsible for the comorbid osteoporosis. Subsequently, inconsistencies in studies linking fracture risk to the action of thyroid hormones versus thyroid autoantibodies means the effect of thyroid dysfunction on bone pathophysiology remains unclear $[125,126]$. Notably, a recent crosssectional population-based study examining the association between calcaneal ultrasound parameters and thyroid status in middle-aged and elderly Chinese men observed high anti-TPO levels $(\geq 200 \mathrm{IU} / \mathrm{mL})$ to be associated with lower QUI $(p=0.030)$ [65]. We failed to observe any significant association between anti-TPO autoantibodies and QUS index.

Previous literature has suggested a role for anti-TTG autoantibodies in bone disease observed to occur alongside conditions such as celiac disease, ankylosing spondylitis, and psoriatic arthritis $[127,128]$. Moreover, anti-TTG autoantibodies have previously been shown to act as a marker of low BMD as well as high fracture frequency amongst an asymptomatic celiac disease population sample $[18,22]$. Our study was unable to find any evidence of a statistically significant relationship between these autoantibodies and QUS index, likely due to low power. Anti-TTG autoantibodies are implicated in pathogenic bone loss through a variety of pathways. In particular, TTG has recently been identified as a regulator of receptor activator of nuclear factor kappa beta ligand (RANKL) production as well as myeloid and mesenchymal stem cell (MSC) differentiation [32]. The latter two cell types are the major precursors for osteoclasts and osteoblasts, respectively, whilst RANKL is the key factor for maturation, proliferation, and fusion of preosteoclasts as well as osteoclast activation and survival [13]. Inactivation of TTG by anti-TTG autoantibodies may therefore carry serious implications for bone homeostasis.

Anti-TTG and anti-TPO autoantibody cooccurrence was noted to significantly and negatively correlate with QUS index amongst our elderly sample ( $r=-0.85 ; 95 \%$ CI: -1.63 to $-0.06 ; p=0.036)$. Similarly, ANCA and ACGA autoantibody coexpression was also noted to significantly decrease QUS index in our sample ( $r=-0.84$; 95\% CI: -1.53 to $-0.15 ; p=0.017$ ). Anti-TTG and anti-TPO autoantibodies have been reported in celiac disease sufferers who develop thyroid dysfunction [129]. Alternatively, ANCA and ACGA have been reported to cooccur in anti-neutrophil cytoplasmic autoantibody-associated diseases, primary sclerosing cholangitis and glomerulonephritis [130-132]. Unlike TPO and TTG, there is a lack of literature linking ANCA and ACGA to pathologic bone loss. Indeed, our observations may be an incidental abnormality as very few healthy individuals when screened would be expected to be positive for ANCA and ACGA. However, we cannot disregard the potential impact these autoantibodies, when coexpressed, might have on bone. Nonetheless, the significance of the coexpression of the latter autoantibodies in relation to bone fragility required further investigation.

Our study is not without its limitations. Firstly, the use of a nonclinical population sample significantly affected the prevalence of autoantibodies and therefore our ability to detect any clinically significant effect on QUS index. Furthermore, it was assumed that a vast majority of our female sample would already have entered menopause; therefore, this data was not collected and we were subsequently unable to control for its influence on the relationship between QUS index and autoantibody positivity. Moreover, our measurement of amount of physical activity rather than loading which is acknowledged to be a more important mediator of bone health may have affected our ability to accurately delineate the relationship between physical activity and QUS index. Similarly, our failure to account for dietary calcium and vitamin $\mathrm{D}$ intake may have also affected our ability to correctly describe the relationship between the latter nutrients and QUS index. Furthermore, we must acknowledge the potential for bias based on our use of self-report questionnaires. Additionally, our study is based on the assessment of an elderly Caucasian sample and therefore extrapolation of our findings beyond this group should be taken with caution. Nonetheless, the study is significantly strengthened by its use of standardised methods in the assessment of study characteristics amongst our sample drawn from the general population.

\section{Conclusion}

Existing research has linked high autoantibody titres to bone loss observed to occur alongside a variety of autoimmune diseases as well as present amongst the elderly. However, our study findings did not support the notion that autoantibodies are causative in bone disease. As previously mentioned, the use of a nonclinical population sample significantly affected the prevalence of autoantibodies and therefore our ability to detect any clinically significant effect on QUS index. Moreover, due to the cross-sectional nature of this study, this is purely explorative research. It would therefore be premature to conclude that autoantibodies have no impact on bone mass. Investigating the health impact of autoimmunity on bone health is important as it can point to latent or clinically silent forms of osteoporosis. Serological tests for autoimmunity could then be used to identify individuals with no or atypical symptoms at a time when QUS or DEXA are unable to provide any valuable information. The 
significance of autoantibodies in relation to bone health requires further investigation.

\section{Conflicts of Interest}

The authors declare that there is no conflict of interest regarding the publication of this article.

\section{Acknowledgments}

This study was funded by the University of Newcastle Postgraduate Research Scholarship courtesy of the Collaborative Research Network (CRN) for Mental Health and Wellbeing-Scholarship. The Hunter Community Study was conducted by a team of researchers at the University of Newcastle, School of Medicine and Public Health, in collaboration with the Hunter New England Area Health Service. The authors would like to acknowledge and thank both parties for all ongoing support and the use of their data.

\section{References}

[1] G. Mori, P. D'Amelio, R. Faccio, and G. Brunetti, "The interplay between the bone and the immune system," Clinical and Developmental Immunology, vol. 2013, article 720504, 16 pages, 2013.

[2] X. Feng and J. M. McDonald, "Disorders of bone remodeling," Annual Review of Pathology, vol. 6, no. 1, pp. 121-145, 2011.

[3] J. R. Geissler, D. Bajaj, and J. C. Fritton, “American Society of Biomechanics Journal of Biomechanics Award 2013: cortical bone tissue mechanical quality and biological mechanisms possibly underlying atypical fractures," Journal of Biomechanics, vol. 48, no. 6, pp. 883-894, 2015.

[4] B. Seriolo, S. Paolino, A. Casabella, G. Botticella, C. Seriolo, and L. Molfetta, "Osteoporosis in the elderly," Aging Clinical and Experimental Research, vol. 25, no. S1, pp. 27-29, 2013.

[5] S. R. Goldring, "Inflammatory signaling induced bone loss," Bone, vol. 80, pp. 143-149, 2015.

[6] A. G. Cotter and P. W. G. Mallon, "The effects of untreated and treated HIV infection on bone disease," Current Opinion in HIV and AIDS, vol. 9, no. 1, pp. 17-26, 2014.

[7] M. N. Weitzmann, "T-cells and B-cells in osteoporosis," Current Opinion in Endocrinology, Diabetes, and Obesity, vol. 21, no. 6, pp. 461-467, 2014.

[8] J. A. Clowes, B. L. Riggs, and S. Khosla, "The role of the immune system in the pathophysiology of osteoporosis," Immunological Reviews, vol. 208, no. 1, pp. 207-227, 2005.

[9] F. Arai, T. Miyamoto, O. Ohneda et al., "Commitment and differentiation of osteoclast precursor cells by the sequential expression of C-Fms and receptor activator of nuclear factor $\kappa \mathrm{b}$ (rank) receptors," Journal of Experimental Medicine, vol. 190, no. 12, pp. 1741-1754, 1999.

[10] R. Lindsay and F. Cosman, "Osteoporosis," in Harrison's Principles of Internal Medicine, 19e, D. Kasper, A. Fauci, S. Hauser, D. Longo, J. Jameson, and J. Loscalzo, Eds., McGraw-Hill, New York, NY, USA, 2014.

[11] D. W. Dempster, "Osteoporosis and the burden of osteoporosis-related fractures," The American Journal of Managed Care, vol. 17, Supplement 6, pp. S164-S169, 2011.
[12] P. Pietschmann, D. Mechtcheriakova, A. Meshcheryakova, U. Föger-Samwald, and I. Ellinger, "Immunology of osteoporosis: a mini-review," Gerontology, vol. 62, no. 2, pp. 128-137, 2016.

[13] R. A. Iseme, M. McEvoy, B. Kelly, L. Agnew, F. R. Walker, and J. Attia, "Is osteoporosis an autoimmune mediated disorder?," Bone Reports, vol. 7, pp. 121-131, 2017.

[14] U. Harre, S. C. Lang, R. Pfeifle et al., "Glycosylation of immunoglobulin $\mathrm{G}$ determines osteoclast differentiation and bone loss," Nature Communications, vol. 6, p. 6651, 2015.

[15] S. Bugatti, L. Bogliolo, C. Montecucco, and A. Manzo, "B cell autoimmunity and bone damage in rheumatoid arthritis," Reumatismo, vol. 68, no. 3, pp. 117-125, 2016.

[16] G. Orsolini, C. Caimmi, O. Viapiana et al., "Titer-dependent effect of anti-citrullinated protein antibodies on systemic bone mass in rheumatoid arthritis patients," Calcified Tissue International, vol. 101, no. 1, pp. 17-23, 2017.

[17] K. Heikkilä, M. Heliövaara, O. Impivaara et al., "Celiac disease autoimmunity and hip fracture risk: findings from a prospective cohort study," Journal of Bone and Mineral Research, vol. 30, no. 4, pp. 630-636, 2015.

[18] D. Agardh, S. Bjorck, C.-D. Agardh, and J. Lidfeldt, "Coeliac disease-specific tissue transglutaminase autoantibodies are associated with osteoporosis and related fractures in middle-aged women," Scandinavian Journal of Gastroenterology, vol. 44, no. 5, pp. 571-578, 2009.

[19] H. W. van Steenbergen, S. Ajeganova, K. Forslind, B. Svensson, and A. H. M. van der Helm-van Mil, "The effects of rheumatoid factor and anticitrullinated peptide antibodies on bone erosions in rheumatoid arthritis," Annals of the Rheumatic Diseases, vol. 74, no. 1, p. e3, 2014.

[20] A. Mak, J. Q. Lim, Y. Liu, A. A. Cheak, and R. C. Ho, "Significantly higher estimated 10-year probability of fracture in lupus patients with bone mineral density comparable to that of healthy individuals," Rheumatology International, vol. 33, no. 2, pp. 299-307, 2013.

[21] T. Larussa, E. Suraci, I. Nazionale et al., "No evidence of circulating autoantibodies against osteoprotegerin in patients with celiac disease," World Journal of Gastroenterology, vol. 18, no. 14, pp. 1622-1627, 2012.

[22] J. West, R. F. A. Logan, P. G. Hill, and K.-. T. Khaw, "The iceberg of celiac disease: what is below the waterline?," Clinical Gastroenterology and Hepatology, vol. 5, no. 1, pp. 59-62, 2007.

[23] W. Dickey, D. F. Hughes, and S. A. McMillan, "Patients with serum IgA endomysial antibodies and intact duodenal villi: clinical characteristics and management options," Scandinavian Journal of Gastroenterology, vol. 40, no. 10, pp. 12401243, 2005.

[24] K. Kurppa, P. Collin, H. Sievanen, H. Huhtala, M. Maki, and K. Kaukinen, "Gastrointestinal symptoms, quality of life and bone mineral density in mild enteropathic coeliac disease: a prospective clinical trial," Scandinavian Journal of Gastroenterology, vol. 45, no. 3, pp. 305-314, 2010.

[25] K. Mustalahti, P. Collin, H. Sievanen, J. Salmi, and M. Maki, "Osteopenia in patients with clinically silent coeliac disease warrants screening," The Lancet, vol. 354, no. 9180, pp. 744-745, 1999.

[26] A. Kleyer, S. Finzel, J. Rech et al., "Bone loss before the clinical onset of rheumatoid arthritis in subjects with 
anticitrullinated protein antibodies," Annals of the Rheumatic Diseases, vol. 73, no. 5, pp. 854-860, 2014.

[27] S. Bugatti, L. Bogliolo, B. Vitolo, A. Manzo, C. Montecucco, and R. Caporali, "Anti-citrullinated protein antibodies and high levels of rheumatoid factor are associated with systemic bone loss in patients with early untreated rheumatoid arthritis," Arthritis Research \& Therapy, vol. 18, no. 1, p. 226, 2016.

[28] I. Llorente, L. Merino, A. M. Ortiz et al., "Anti citrullinated protein antibodies are associated with decreased bone mineral density: baseline data from a register of early arthritis patients," Rheumatology International, vol. 37, no. 5, pp. 799-806, 2017.

[29] F. Vaziri-Sani, C. Brundin, and D. Agardh, “Osteoprotegerin autoantibodies do not predict low bone mineral density in middle-aged women," Bone Reports, vol. 7, pp. 132-136, 2017.

[30] T. Takai, A. Nakamura, A. Tobinai, S. Endo, and M. Inui, "Fc $\gamma$ receptor targeting in RA," Arthritis Research \& Therapy, vol. 14, Supplement 1, p. 17, 2012.

[31] U. Harre, N. A. Kittan, and G. Schett, "Autoantibody mediated bone loss," Current Osteoporosis Reports, vol. 12, no. 1, pp. 17-21, 2014.

[32] A. Mousa, C. Cui, A. Song et al., "Transglutaminases factor XIII-A and TG2 regulate resorption, adipogenesis and plasma fibronectin homeostasis in bone and bone marrow," Cell Death and Differentiation, vol. 24, no. 5, pp. 844-854, 2017.

[33] P. Pisani, M. D. Renna, F. Conversano et al., "Screening and early diagnosis of osteoporosis through $\mathrm{X}$ ray and ultrasound based techniques," World Journal of Radiology, vol. 5, no. 11, pp. 398-410, 2013.

[34] H. Fonseca, D. Moreira-Gonçalves, H.-J. A. Coriolano, and J. A. Duarte, "Bone quality: the determinants of bone strength and fragility," Sports Medicine, vol. 44, no. 1, pp. 37-53, 2014.

[35] D. Haus, C. F. Njeh, H. K. Genant, and P. J. Meunier, "Qualitative ultrasound in bone status assessment," Revue $D u$ Rhumatisme, vol. 65, pp. 489-498, 1998.

[36] I. Yoshimi, K. Aoyagi, K. Okano et al., "Stiffness index of the calcaneus measured by quantitative ultrasound and menopause among Japanese women: the Hizen-Oshima Study," The Tohoku Journal of Experimental Medicine, vol. 195, no. 2, pp. 93-99, 2001.

[37] J. A. Kanis, E. V. McCloskey, D. de Takats, and K. Pande, "Clinical assessment of bone mass, quality and architecture," Osteoporosis International, vol. 9, no. S2, Supplement 2, pp. S24-S28, 1999.

[38] Y. Rhee, J. Lee, J. Y. Jung et al., "Modifications of T score by qualitative ultrasonography for the diagnosis of osteoporosis in Koreans," Journal of Korean Medical Science, vol. 24, no. 2, pp. 232-236, 2009.

[39] S. S. Yeap, D. Pearson, S. A. Cawte, and D. J. Hosking, "The relationship between bone mineral density and ultrasound in postmenopausal and osteoporotic women," Osteoporosis International, vol. 8, no. 2, pp. 141-146, 1998.

[40] S. M. F. Pluijm, W. C. Graafmans, L. M. Bouter, and P. Lips, "Ultrasound measurements for the prediction of osteoporotic fractures in elderly people," Osteoporosis International, vol. 9, no. 6, pp. 550-556, 1999.

[41] M. B. Mikhail, E. Flaster, and J. F. Aloia, "Stiffness in discrimination of patients with vertebral fractures," Osteoporosis International, vol. 9, no. 1, pp. 24-28, 1999.
[42] E. Toussirot, F. Michel, and D. Wendling, "Bone density, ultrasound measurements and body composition in early ankylosing spondylitis," Rheumatology, vol. 40, no. 8, pp. 882-888, 2001.

[43] A. Moayyeri, J. E. Adams, R. A. Adler et al., "Quantitative ultrasound of the heel and fracture risk assessment: an updated meta-analysis," Osteoporosis International, vol. 23, no. 1, pp. 143-153, 2012.

[44] T. Kwok, C. C. Khoo, J. Leung et al., "Predictive values of calcaneal quantitative ultrasound and dual energy $\mathrm{X}$ ray absorptiometry for non-vertebral fracture in older men: results from the MrOS study (Hong Kong)," Osteoporosis International, vol. 23, no. 3, pp. 1001-1006, 2012.

[45] J. L. Hernández, F. Marin, J. González-Macías et al., "Discriminative capacity of calcaneal quantitative ultrasound and of osteoporosis and fracture risk factors in postmenopausal women with osteoporotic fractures," Calcified Tissue International, vol. 74, no. 4, pp. 357-365, 2004.

[46] K.-Y. Chin and S. Ima-Nirwana, "Calcaneal quantitative ultrasound as a determinant of bone health status: what properties of bone does it reflect?," International Journal of Medical Sciences, vol. 10, no. 12, pp. 1778-1783, 2013.

[47] M. W. Taal, M. J. D. Cassidy, D. Pearson, D. Green, and T. Masud, "Usefulness of quantitative heel ultrasound compared with dual-energy X-ray absorptiometry in determining bone mineral density in chronic haemodialysis patients," Nephrology, Dialysis, Transplantation, vol. 14, no. 8, pp. 1917-1921, 1999.

[48] L. Zhang, H. Lv, H. Zheng et al., "Correlation between parameters of calcaneal quantitative ultrasound and hip structural analysis in osteoporotic fracture patients," PLoS One, vol. 10, no. 12, article e0145879, 2015.

[49] J. J. Goronzy and C. M. Weyand, "Immune aging and autoimmunity," Cellular and Molecular Life Sciences, vol. 69, no. 10, pp. 1615-1623, 2012.

[50] Z. Vadasz, T. Haj, A. Kessel, and E. Toubi, "Age-related autoimmunity," BMC Medicine, vol. 11, no. 1, p. 94, 2013.

[51] J. A. Cauley, "Public health impact of osteoporosis," The Journals of Gerontology Series A, vol. 68, no. 10, pp. 1243-1251, 2013.

[52] J. R. Tucci, "Importance of early diagnosis and treatment of osteoporosis to prevent fractures," The American Journal of Managed Care, vol. 12, Supplement 7, pp. S181-S190, 2006.

[53] M. McEvoy, W. Smith, C. D'Este et al., "Cohort profile: the Hunter Community Study," International Journal of Epidemiology, vol. 39, no. 6, pp. 1452-1463, 2010.

[54] M. Correa-Rodríguez, J. S. Rio-Valle, E. González-Jiménez, and B. Rueda-Medina, "A cross-sectional study of the association of VDR gene, calcium intake and heel ultrasound measures in early adulthood," Calcified Tissue International, vol. 98, no. 3, pp. 226-234, 2016.

[55] A. Moayyeri, S. Kaptoge, N. Dalzell et al., "Is QUS or DXA better for predicting the 10-year absolute risk of fracture?" Journal of Bone and Mineral Research, vol. 24, no. 7, pp. 1319-1325, 2009.

[56] D. Hans, C. Durosier, J. A. Kanis, H. Johansson, A.-M. SchottPethelaz, and M.-A. Krieg, "Assessment of the 10-year probability of osteoporotic hip fracture combining clinical risk factors and heel bone ultrasound: the EPISEM prospective cohort of 12,958 elderly women," Journal of Bone and Mineral Research, vol. 23, no. 7, pp. 1045-1051, 2008. 
[57] S. Harris and B. Dawson-Hughes, "Rates of change in bone mineral density of the spine, heel, femoral neck and radius in healthy postmenopausal women," Bone and Mineral, vol. 17, no. 1, pp. 87-95, 1992.

[58] H. D. Lee, H. F. Hwang, and M. R. Lin, "Use of quantitative ultrasound for identifying low bone density in older people," Journal of Ultrasound in Medicine, vol. 29, no. 7, pp. 10831092, 2010.

[59] M. H. Shin, S. S. Kweon, K. S. Park et al., "Quantitative ultrasound of the calcaneus in a Korean population: reference data and relationship to bone mineral density determined by peripheral dual X-ray absorptiometry," Journal of Korean Medical Science, vol. 20, no. 6, pp. 1011-1016, 2005.

[60] M. S. Holi, S. Radhakrishnan, S. Swaranamani, and N. A. Jayavelan, "Quantitative ultrasound technique for the assessment of osteoporosis and prediction of fracture risk," Journal of Pure and Applied Ultrasonics, vol. 27, pp. 55-60, 2005.

[61] S. Greenland, J. Pearl, and J. M. Robins, "Causal diagrams for epidemiologic research," Epidemiology, vol. 10, no. 1, pp. 3748, 1999.

[62] R. Bouillon and T. Suda, "Vitamin D: calcium and bone homeostasis during evolution," BoneKEy Reports, vol. 3, p. 480, 2014.

[63] C. E. Collins, A. F. Young, and A. Hodge, "Diet quality is associated with higher nutrient intake and self-rated health in mid-aged women," Journal of the American College of Nutrition, vol. 27, no. 1, pp. 146-157, 2008.

[64] StataCorp, Stata Statistical Software: Release 11, StataCorp LP, College Station, TX, USA, 2009.

[65] Y. Shin, M. Sun, Z. Wang et al., "Association between calcaneus quantitative ultrasound (QUS) parameters and thyroid status in middle-aged and elderly Chinese men with euthyroidism: a population-based cross-sectional study," Endocrine, vol. 47, no. 1, pp. 227-233, 2014.

[66] P. Trimpou, I. Bosaeus, B.-A. Bengtsson, and K. LandinWilhelmsen, "High correlation between quantitative ultrasound and DXA during 7 years of follow-up," European Journal of Radiology, vol. 73, no. 2, pp. 360-364, 2010.

[67] K. A. Wear, S. Nagaraja, M. L. Dreher, and S. L. Gibson, "Relationships of quantitative ultrasound parameters with cancellous bone microstructure in human calcaneus in vitro," The Journal of the Acoustical Society of America, vol. 131, no. 2, pp. 1605-1612, 2012.

[68] C. Dane, B. Dane, A. Cetin, and M. Erginbas, "The role of quantitative ultrasound in predicting osteoporosis defined by dual-energy X-ray absorptiometry in pre- and postmenopausal women," Climacteric, vol. 11, no. 4, pp. 296-303, 2008.

[69] J. L. Hernández, F. Marin, J. González-Macías et al., "Discriminative capacity of calcaneal quantitative ultrasound and of osteoporosis and fracture risk factors in postmenopausal women with osteoporotic fractures," Calcified Tissue International, vol. 74, no. 4, pp. 357-365, 2004.

[70] T. F. Lang, "The bone-muscle relationship in men and women," Journal of Osteoporosis, vol. 2011, Article ID 702735, 4 pages, 2011.

[71] P. M. Cawthon, "Gender differences in osteoporosis and fractures," Clinical Orthopaedics and Related Research, vol. 469, no. 7, pp. 1900-1905, 2011.

[72] K. D. Ward and R. C. Klesges, "A meta-analysis of the effects of cigarette smoking on bone mineral density," Calcified Tissue International, vol. 68, no. 5, pp. 259-270, 2001.
[73] F. A. Tylavsky, L. D. Carbone, and A. J. Bush, "Effects of ethnicity and gender on reliable measurements using the sahara ultrasonometer," Journal of Clinical Densitometry, vol. 5, no. 4, pp. 411-419, 2002.

[74] I. Kyvernitakis, U. Saeger, V. Ziller, T. Bauer, B. Seker-Pektas, and P. Hadji, "The effect of age, sex hormones, and bone turnover markers on calcaneal quantitative ultrasonometry in healthy German men," Journal of Clinical Densitometry, vol. 16, no. 3, pp. 320-328, 2013.

[75] M. L. Frost, G. M. Blake, and I. Fogelman, "Contact quantitative ultrasound: an evaluation of precision, fracture discrimination, age-related bone loss and applicability of the WHO criteria," Osteoporosis International, vol. 10, no. 6, pp. 441449, 1999.

[76] K. Pätzug, N. Friedrich, H. Kische et al., "Sex hormones and quantitative ultrasound parameters at the heel in men and women from the general population," Bone Reports, vol. 7, pp. 51-56, 2017.

[77] E. Seeman, "Growth in bone mass and size-are racial and gender differences in bone mass density more apparent than real?," The Journal of Clinical Endocrinology \& Metabolism, vol. 83, no. 5, pp. 1414-1419, 1998.

[78] X. P. Wu, Y. H. Yang, H. Zhang et al., "Gender differences in bone density at different skeletal sites of acquisition with age in Chinese children and adolescents," Journal of Bone and Mineral Metabolism, vol. 23, no. 3, pp. 253-260, 2005.

[79] M. Sosa, P. Saavedra, M. Muñoz-Torres et al., "Quantitative ultrasound calcaneus measurements: normative data and precision in the Spanish population," Osteoporosis International, vol. 13, no. 6, pp. 487-492, 2002.

[80] K. A. Alswat, "Gender disparities in osteoporosis," Journal of Clinical Medicine Research, vol. 9, no. 5, pp. 382-387, 2017.

[81] Z. Ding, Y. Chen, Y. Xu et al., "Impact of age, gender, and body composition on bone quality in an adult population from the middle areas of China," Journal of Clinical Densitometry, vol. 21, no. 1, pp. 83-90, 2018.

[82] D. T. Felson, Y. Zhang, M. T. Hannan, and J. J. Anderson, "Effects of weight and body mass index on bone mineral density in men and women: the Framingham study," Journal of Bone and Mineral Research, vol. 8, no. 5, pp. 567-573, 1993.

[83] S. Gonnelli, C. Caffarelli, L. Tanzilli et al., "The association of body composition and sex hormones with quantitative ultrasound parameters at the calcaneus and phalanxes in elderly women," Calcified Tissue International, vol. 89, no. 6, pp. 456-463, 2011.

[84] C. Brunner, J. Pons-Kühnemann, and M. NeuhäuserBerthold, "Impact of age, anthropometric data and body composition on calcaneal bone characteristics, as measured by quantitative ultrasound (QUS) in an older German population," Ultrasound in Medicine \& Biology, vol. 37, no. 12, pp. 1984-1992, 2011.

[85] S. R. Pye, V. Devakumar, S. Boonen et al., "Influence of lifestyle factors on quantitative heel ultrasound measurements in middle-aged and elderly men," Calcified Tissue International, vol. 86, no. 3, pp. 211-219, 2010.

[86] H. Canhao, R. Lucas, J. E. Fonseca et al., "Factors influencing calcaneus quantitative ultrasound measurements in an urban population," Clinical and Experimental Rheumatology, vol. 26, no. 1, pp. 67-72, 2008. 
[87] M. Kauppi, O. Impivaara, J. Mäki et al., "Vitamin D status and common risk factors for bone fragility as determinants of quantitative ultrasound variables in a nationally representative population sample," Bone, vol. 45, no. 1, pp. 119-124, 2009.

[88] A. Welch, J. Camus, N. Dalzell, S. Oakes, J. Reeve, and K. T. Khaw, "Broadband ultrasound attenuation (BUA) of the heel bone and its correlates in men and women in the EPICNorfolk cohort: a cross-sectional population-based study," Osteoporosis International, vol. 15, no. 3, pp. 217-225, 2004.

[89] E. Babaroutsi, F. Magkos, Y. Manios, and L. S. Sidossis, "Body mass index, calcium intake, and physical activity affect calcaneal ultrasound in healthy Greek males in an age-dependent and parameter-specific manner," Journal of Bone and Mineral Metabolism, vol. 23, no. 2, pp. 157-166, 2005.

[90] S. Adami, S. Giannini, R. Giorgino et al., "The effect of age, weight, and lifestyle factors on calcaneal quantitative ultrasound: the ESOPO study," Osteoporosis International, vol. 14, no. 3, pp. 198-207, 2005.

[91] M. Kostecka, "The role of healthy diet in the prevention of osteoporosis in perimenopausal period," Pakistan Journal of Medical Sciences, vol. 30, no. 4, pp. 763-768, 2014.

[92] K.-A. Park, Y.-H. Park, M.-H. Suh, and S. Choi-Kwon, "Lifestyle and genetic predictors of stiffness index in communitydwelling elderly Korean men and women," Asian Nursing Research, vol. 9, no. 3, pp. 251-258, 2015.

[93] L. Méndez-Sánchez, K. López Casimiro, T. M. Winzenberg, P. Tugwell, and P. Clark, "Calcium and vitamin D for increasing bone mineral density in premenopausal women (Protocol)," Cochrane Database of Systematic Reviews, no. 5, article CD012664, 2017.

[94] E. Babaroutsi, F. Magkos, Y. Manios, and L. S. Sidossis, "Lifestyle factors affecting heel ultrasound in Greek females across different life stages," Osteoporosis International, vol. 16, no. 5, pp. 552-561, 2005.

[95] T. M. Winzenberg, K. Shaw, J. Fryer, and G. Jones, “Calcium supplementation for improving bone mineral density in children," Cochrane Database of Systematic Reviews, no. 2, article CD005119, 2006.

[96] S. De Smet, N. Michels, C. Polfliet et al., "The influence of dairy consumption and physical activity on ultrasound bone measurements in Flemish children," Journal of Bone and Mineral Metabolism, vol. 33, no. 2, pp. 192-200, 2015.

[97] Y. Dionyssiotis, I. Paspati, G. Trovas, A. Galanos, and G. P. Lyritis, "Association of physical exercise and calcium intake with bone mass measured by quantitative ultrasound," BMC Women's Health, vol. 10, p. 12, 2010.

[98] P. W. Man, I. M. van der Meer, P. Lips, and B. J. C. Middelkoop, "Vitamin D status and bone mineral density in the Chinese population: a review," Archives of Osteoporosis, vol. 11, no. 1, p. 14, 2016.

[99] I. R. Reid, M. J. Bolland, and A. Grey, "Effects of vitamin D supplements on bone mineral density: a systematic review and meta-analysis," The Lancet, vol. 383, no. 9912, pp. 146155, 2014.

[100] M. A. Krieg, A. F. Jacquet, M. Bremgartner, S. Cuttelod, D. Thiébaud, and P. Burckhardt, "Effect of supplementation with vitamin D3 and calcium on quantitative ultrasound of bone in elderly institutionalized women: a longitudinal study," Osteoporosis International, vol. 9, no. 6, pp. 483488, 1999.
[101] J. J. Anderson, P. Rondano, and A. Holmes, "Roles of diet and physical activity in the prevention of osteoporosis," Scandinavian Journal of Rheumatology, vol. 103, pp. 65-74, 1996.

[102] P. D. Chilibeck, D. G. Sale, and C. E. Webber, "Exercise and bone mineral density," Sports Medicine, vol. 19, no. 2, pp. 103-122, 1995.

[103] N. H. Hart, S. Nimphius, T. Rantalainen, A. Ireland, A. Siafarikas, and R. U. Newton, "Mechanical basis of bone strength: influence of bone material, bone structure and muscle action," Journal of Musculoskeletal and Neuronal Interactions, vol. 17, no. 3, pp. 114-139, 2017.

[104] K. M. Palombaro, "Effects of walking only interventions on bone mineral density at various skeletal sites: a meta-analysis," Journal of Geriatric Physical Therapy, vol. 28, no. 3, pp. 102-107, 2005.

[105] Y. Ibn Yacoub, B. Amine, A. Laatiris, F. Wafki, F. Znat, and N. Hajjaj-Hassouni, "Bone density in Moroccan women with systemic scleroderma and its relationships with diseaserelated parameters and vitamin D status," Rheumatology International, vol. 32, no. 10, pp. 3143-3148, 2012.

[106] M. Marot, A. Valery, E. Esteve et al., "Prevalence and predictive factors of osteoporosis in systemic sclerosis patients: a case-control study," Oncotarget, vol. 6, no. 17, pp. 1486514873, 2015.

[107] M. Cojocaru, I. M. Cojocaru, I. Silosi, and C. D. Vrabie, "Manifestations of systemic lupus erythematosus," Maedica, vol. 6, no. 4, pp. 330-336, 2011.

[108] D. Sen and R. W. Keen, "Osteoporosis in systemic lupus erythematosus: prevention and treatment," Lupus, vol. 10, no. 3, pp. 227-232, 2001.

[109] L. Sinigaglia, M. Varenna, L. Binelli et al., "Determinants of bone mass in systemic lupus erythematosus: a cross sectional study on premenopausal women," The Journal of Rheumatology, vol. 26, no. 6, pp. 1280-1284, 1999.

[110] I. E. M. Bultink, W. F. Lems, P. J. Kostense, B. A. C. Dijkmans, and A. E. Voskuyl, "Prevalence of and risk factors for low bone mineral density and vertebral fractures in patients with systemic lupus erythematosus," Arthritis \& Rheumatism, vol. 52, no. 7, pp. 2044-2050, 2005.

[111] J. Teichmann, U. Lange, H. Stracke, K. Federlin, and R. G. Bretzel, "Bone metabolism and bone mineral density of systemic lupus erythematosus at the time of diagnosis," Rheumatology International, vol. 18, no. 4, pp. 137-140, 1999.

[112] S. A. Jost, L.-C. Tseng, L. A. Matthews et al., "IgG, IgM, and IgA antinuclear antibodies in discoid and systemic lupus erythematosus patients," The Scientific World Journal, vol. 2014, Article ID 171028, 7 pages, 2014.

[113] J. F. Simard and M. Holmqvist, "Rheumatoid factor positivity in the general population," $B M J$, vol. 345 , no. sep06 2, article e5841, 2012.

[114] F. Ingegnoli, R. Castelli, and R. Gualtierotti, "Rheumatoid factors: clinical applications," Disease Markers, vol. 35, no. 6, 734 pages, 2013.

[115] A. G. Juby, P. Davis, J. E. McElhaney, and S. Gravenstein, "Prevalence of selected autoantibodies in different elderly subpopulations," British Journal of Rheumatology, vol. 33, no. 12, pp. 1121-1124, 1994.

[116] C. Hecht, G. Schett, and S. Finzel, "The impact of rheumatoid factor and ACPA on bone erosion in rheumatoid arthritis," 
Annals of the Rheumatic Diseases, vol. 74, no. 1, article e4, 2014.

[117] M. Seeling and F. Nimmerjahn, "Unlocking the bone: Fc $\gamma$ receptors and antibody glycosylation are keys to connecting bone homeostasis to humoral immunity," Annals of Translational Medicine, vol. 3, no. 12, p. 163, 2015.

[118] T. Takai, "Fc receptors and their role in immune regulation and autoimmunity," Journal of Clinical Immunology, vol. 25, no. 1, pp. 1-18, 2005.

[119] L. Johansson, F. Pratesi, M. Brink et al., "Antibodies directed against endogenous and exogenous citrullinated antigens pre-date the onset of rheumatoid arthritis," Arthritis Research \& Therapy, vol. 18, no. 1, p. 127, 2016.

[120] U. Harre, D. Georgess, H. Bang et al., "Induction of osteoclastogenesis and bone loss by human autoantibodies against citrullinated vimentin," The Journal of Clinical Investigation, vol. 122, no. 5, pp. 1791-1802, 2012.

[121] R. Kocijan, U. Harre, and G. Schett, "ACPA and bone loss in rheumatoid arthritis," Current Rheumatology Reports, vol. 15, no. 10, p. 366, 2013.

[122] A. Budhram, R. Chu, S. Rusta-Sallehy et al., "Anti-cyclic citrullinated peptide antibody as a marker of erosive arthritis in patients with systemic lupus erythematosus: a systematic review and meta-analysis," Lupus, vol. 23, no. 11, pp. 1156$1163,2014$.

[123] G. Schett and E. Gravallese, "Bone erosion in rheumatoid arthritis: mechanisms, diagnosis and treatment," Nature Reviews Rheumatology, vol. 8, no. 11, pp. 656-664, 2012.

[124] A. Svare, T. I. L. Nilsen, B. O. Asvold et al., "Does thyroid function influence fracture risk? Prospective data from the HUNT2 study, Norway," European Journal of Endocrinology, vol. 169, no. 6, pp. 845-852, 2013.

[125] I. Lambrinoudaki, E. Armeni, P. Pliatsika et al., "Thyroid function and autoimmunity are associated with the risk of vertebral fractures in postmenopausal women," Journal of Bone and Mineral Metabolism, vol. 35, no. 2, pp. 227-233, 2017.

[126] D. Tuchendler and M. Bolanowski, "The influence of thyroid dysfunction on bone metabolism," Thyroid Research, vol. 7, no. 1, p. 12, 2014.

[127] E. Sugai, A. Cherñavsky, S. Pedreira et al., "Bone-specific antibodies in sera from patients with celiac disease: characterization and implications in osteoporosis," Journal of Clinical Immunology, vol. 22, no. 6, pp. 353-362, 2002.

[128] J. Teichmann, M. J. Voglau, and U. Lange, "Antibodies to human tissue transglutaminase and alterations of vitamin D metabolism in ankylosing spondylitis and psoriatic arthritis," Rheumatology International, vol. 30, no. 12, pp. 1559-1563, 2010.

[129] A. Lerner, P. Jeremias, and T. Matthias, "Gut-thyroid axis and celiac disease," Endocrine Connections, vol. 6, no. 4, pp. R52-R58, 2017.

[130] J. A. Savige, L. Chang, D. Wilson, and R. R. C. Buchanan, "Autoantibodies and target antigens in antineutrophil cytoplasmic antibody (ANCA)-associated vasculitides," Rheumatology International, vol. 16, no. 3, pp. 109-114, 1996.
[131] P.-A. Jarrot, L. Chiche, B. Hervier et al., "Systemic lupus erythematosus and antineutrophil cytoplasmic antibody-associated vasculitis overlap syndrome in patients with biopsy-proven glomerulonephritis," Medicine, vol. 95, no. 22, article e3748, 2016.

[132] J. R. Hov, K. M. Boberg, and T. H. Karlsen, "Autoantibodies in primary sclerosing cholangitis," World Journal of Gastroenterology, vol. 14, no. 24, pp. 3781-3791, 2008. 


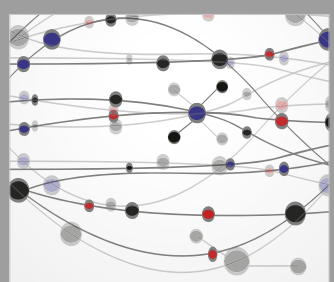

The Scientific World Journal
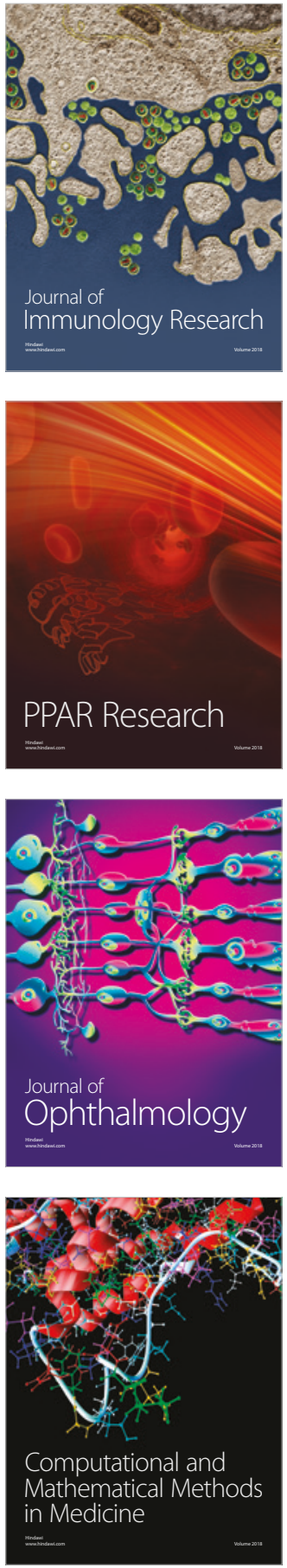

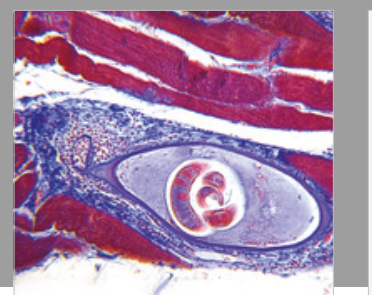

Gastroenterology Research and Practice

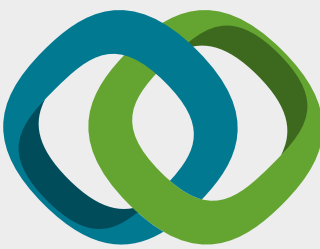

\section{Hindawi}

Submit your manuscripts at

www.hindawi.com
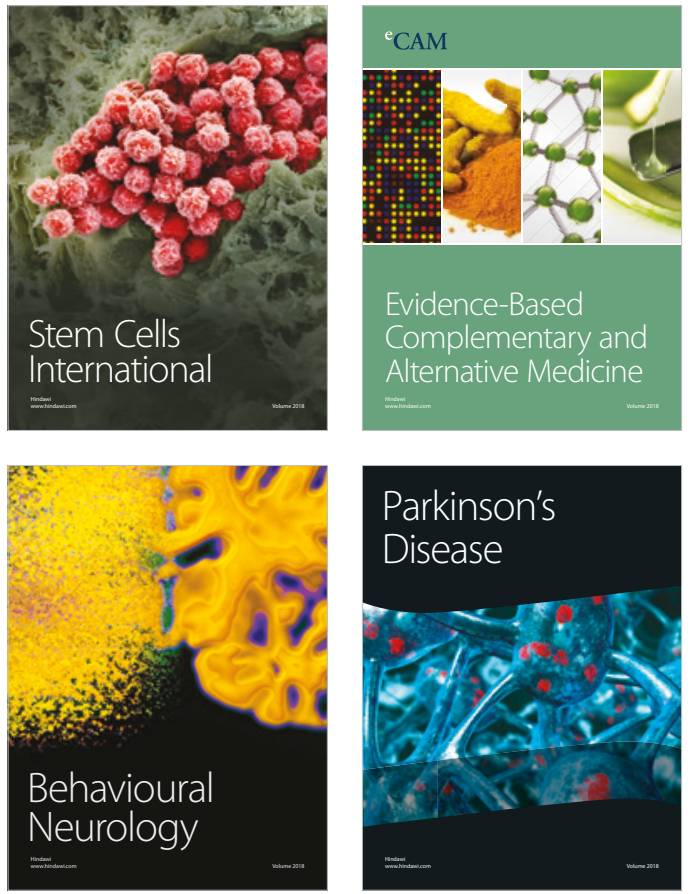

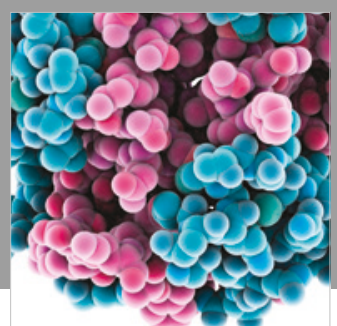

ournal of

Diabetes Research

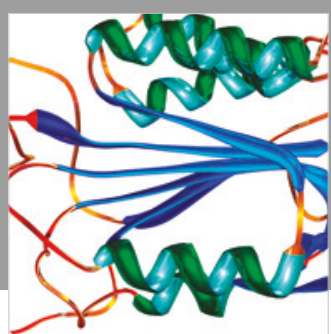

Disease Markers
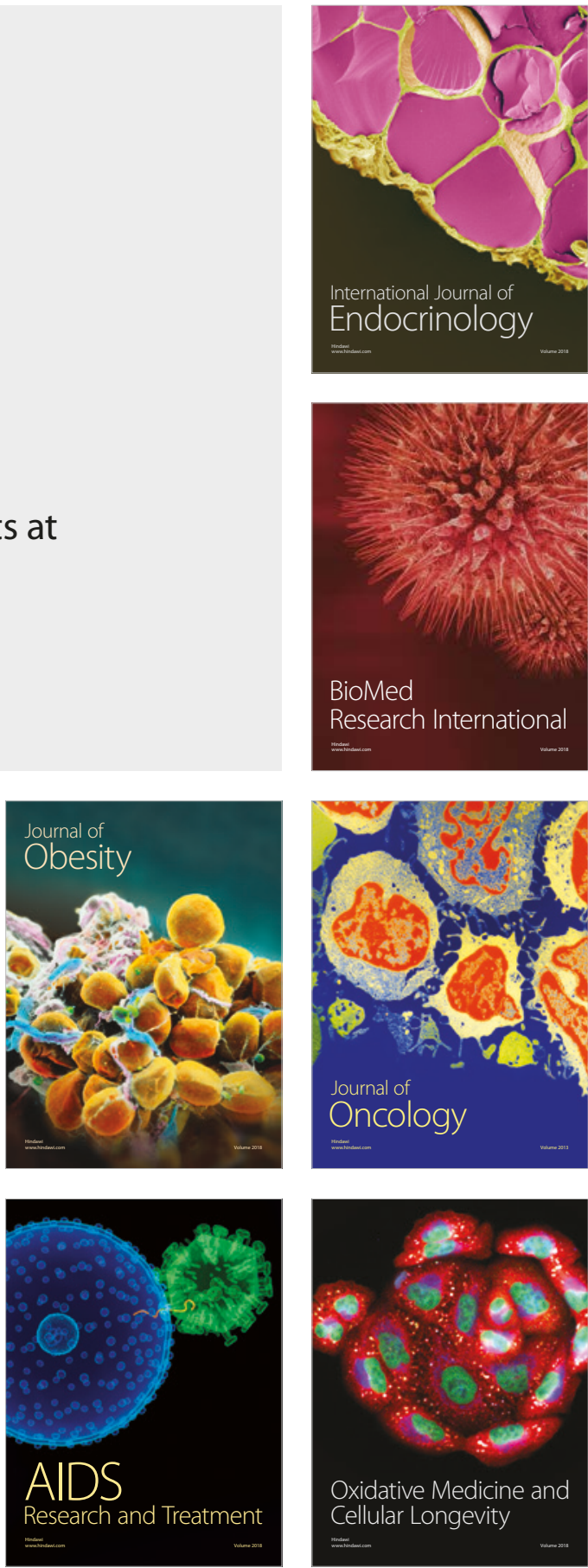